\title{
Laboratory studies of fresh and aged biomass burning aerosol emitted from east African biomass fuels - Part 2: Chemical properties and characterization
}

\author{
Damon M. Smith ${ }^{1,2, a}$, Tianqu Cui ${ }^{4, b}$, Marc N. Fiddler ${ }^{3}$, Rudra P. Pokhrel ${ }^{1}$, Jason D. Surratt ${ }^{4}$, and Solomon Bililign ${ }^{1}$ \\ ${ }^{1}$ Department of Physics, North Carolina Agricultural and Technical State University, Greensboro, NC 27411, USA \\ ${ }^{2}$ Applied Sciences and Technology Program, North Carolina A \& T State University, Greensboro, NC 27411, USA \\ ${ }^{3}$ Department of Chemistry, North Carolina Agricultural and Technical State University, Greensboro, NC 27411, USA \\ ${ }^{4}$ Department of Environmental Science and Engineering, Gillings School of Global Public Health, \\ University of North Carolina, Chapel Hill, NC 27599, USA \\ ${ }^{a}$ current address: Department of Chemistry and Physics, Western Carolina University, Cullowhee, NC 28723, USA \\ b current address: Laboratory of Atmospheric Chemistry, Paul Scherrer Institute, Villigen 5232, Switzerland
}

Correspondence: Solomon Bililign (bililign@ ncat.edu)

Received: 26 December 2019 - Discussion started: 14 April 2020

Revised: 3 August 2020 - Accepted: 7 August 2020 - Published: 2 September 2020

\begin{abstract}
There are many fuels used for domestic purposes in east Africa, producing a significant atmospheric burden of the resulting aerosols, which includes biomass burning particles. However, the aerosol physicochemical properties are poorly understood. Here, the combustion of eucalyptus, acacia, and olive fuels was performed at 500 and $800^{\circ} \mathrm{C}$ in a tube furnace, followed by immediate filter collection for fresh samples or introduction into a photochemical chamber to simulate atmospheric photochemical aging under the influence of anthropogenic emissions. The aerosol generated in the latter experiment was collected onto filters after $12 \mathrm{~h}$ of photochemical aging. 500 and $800^{\circ} \mathrm{C}$ were selected to simulate smoldering and flaming combustion, respectively, and to cover a range of combustion conditions. Methanol extracts from Teflon filters were analyzed by ultra-performance liquid chromatography interfaced to both a diode array detector and an electrospray ionization high-resolution quadrupole time-of-flight mass spectrometer (UPLC/DAD-ESI-HR-QTOFMS) to determine the light absorption properties of biomass burning organic aerosol constituents chemically characterized at the molecular level. Few chemical or UV-visible (UV: ultraviolet) differences were apparent between samples for the fuels when combusted at $800^{\circ} \mathrm{C}$. Differences in single-scattering albedo (SSA) between fresh samples at this temperature were attributed to
\end{abstract}

compounds not captured in this analysis, with eucalyptol being one suspected missing component. For fresh combustion at $500^{\circ} \mathrm{C}$, many species were present; lignin pyrolysis and distillation products are more prevalent in eucalyptus, while pyrolysis products of cellulose and at least one nitro-aromatic species were more prevalent in acacia. SSA trends are consistent with this, particularly if the absorption of those chromophores extends to the $500-570 \mathrm{~nm}$ region. Upon aging, both show that resorcinol or catechol was removed to the highest degree, and both aerosol types were dominated by loss of pyrolysis and distillation products, though they differed in the specific compounds being consumed by the photochemical aging process.

\section{Introduction}

This is the second part of the two-part laboratory measurement of the optical and chemical properties of biomass burning (BB) aerosols emitted by east African fuels, focused on chemical properties. Biomass fuels were combusted at two different temperatures: combustion at $500^{\circ} \mathrm{C}$ corresponds to a smoldering-dominated fire, which leads to the formation of large quantities of molecular organic compounds and brown carbon $(\mathrm{BrC})$ constituents in the resulting aerosol (Collier 
et al., 2016). These smoldering BB aerosols typically have modified combustion efficiency (MCE) values $<0.9$. Combustion at $800^{\circ} \mathrm{C}$ corresponds to a flaming-dominated fire that mainly forms black carbon (BC) aerosols (Reid et al., 2005) with MCE values $>0.9$. Given the lack of MCE measurements for wildfires and cookstoves in east Africa, a range of combustion conditions were covered in this work. This also highlights the paucity of available measurements of combustion conditions in Africa and the need for such measurements so that appropriate laboratory-scale experiments can be performed.

A soot photometer aerosol mass spectrometer (SPAMS) characterization of the chemical composition of BCcontaining aerosol emitted by BB fuel sources was conducted during the Fire Lab at Missoula Experiments (FLAME) (McClure et al., 2020; May et al., 2014). The work focused on analyzing variations in the particle composition as a function of fuel and combustion conditions. Differences in the refractory black carbon (rBC) were observed with some fuel sources. Organic species were found to vary by orders of magnitude relative to $\mathrm{rBC}$, depending on the fuel source. Chemical differences were also observed between the aged and fresh samples (Fortner et al., 2018).

A component of organic aerosol, $\mathrm{BrC}$, has emerged as a significant type of $\mathrm{BB}$ aerosol. Also known as lightabsorbing organic carbon, $\mathrm{BrC}$ in atmospheric particles has received much attention for its potential role in global radiative forcing (Qin et al., 2018). Primary organic aerosol (POA) contributes an estimated $10 \%$ of total solar absorption by BB aerosols, while aged OA contributes an estimated $30 \%$, making secondary organic aerosol (SOA) production an important source of $\mathrm{BrC}$ (Kumar et al., 2018). As few as 20$25 \mathrm{BrC}$ chromophores are responsible for $40 \%-50 \%$ of total ultraviolet (UV) absorbance in the $300-500 \mathrm{~nm}$ range (Laskin et al., 2018). While several field measurement campaigns have differentiated light absorption by $\mathrm{BC}$ and $\mathrm{BrC}$, the chemical characteristics of $\mathrm{BrC}$ are not currently well understood (Qin et al., 2018).

$\mathrm{BrC}$ is often associated with emissions from incomplete combustion (Andreae and Gelencsér, 2006) but can also form via secondary reactions in the atmosphere (Laskin et al., 2015). Aerosols obtained from a $500^{\circ} \mathrm{C}$ burn classified as $\mathrm{BrC}$ aerosol are spherical in morphology as seen in transmission electron microscopy (TEM) images and are yellowbrown in color due to values of the imaginary portion of the refractive index $(\kappa)$ that increase sharply toward shorter visible and ultraviolet wavelengths (Bond and Bergstrom, 2006). $\mathrm{BrC}$ is comprised of a wide range of poorly characterized compounds exhibiting highly variable light absorption properties, with reported $\kappa$ values spanning 2 orders of magnitude (Saleh et al., 2013; Chen and Bond, 2010; Kirchstetter et al., 2004; McMeeking et al., 2009). Its optical properties have been shown to change through atmospheric processing, such as oxidation and the absorption of solar radiation, leading to particle-phase reactions and aqueous-phase processing within aerosol particles (Lambe et al., 2011, 2013; Sareen et al., 2013; Lee et al., 2014; Zhao et al., 2015; Nguyen et al., 2012; Laskin et al., 2015).

These factors make the chemical composition of $\mathrm{BrC}$ dependent on the location and source of fuel (Laskin et al., 2015; Moise et al., 2015). Many BrC chromophores vary significantly among biomass species, although some, such as sinapaldehyde and coniferaldehye, are common among certain types of biomass fuels, such as angiosperms and gymnosperms, respectively. Other chromophores depend on combustion conditions, such as vanillic acid, which has only been observed as a product of smoldering combustion when the MCE is low (Fleming et al., 2020). Further, an effect known as photo-bleaching can occur, whereby POA chromophores can lose their absorptivity or be destroyed entirely when irradiated by UV light for several hours (Laskin et al., 2018). Since the light absorption spectra of organic compounds is dependent on their molecular structure, identifying atmospheric chromophores making up $\mathrm{BrC}$ is essential for understanding the changes in aerosol optical properties (Moise et al., 2015; Kitanovski et al., 2012a; Mohr et al., 2013; Teich et al., 2017; Zhang et al., 2013). Several recent studies have shown that $\mathrm{BrC}$ cannot be separated or easily distinguished from the rest of the organic aerosol (Saleh, 2020). BrC is classified into four optical regions as a continuum associated with a continuum of physicochemical properties, including molecular sizes, volatility, and solubility (Saleh et al., 2018; Saleh, 2020). The language used in this work for $\mathrm{BrC}$ was mainly to contrast it with $\mathrm{BC}$ based on the combustion temperature, which is a decidedly different component of aerosol even if inextricably mixed in BBA.

In the companion paper, Part 1 , we described the laboratory measurements of a fuel-specific study of the optical properties of BB aerosol emitted by three different fuels sourced from east Africa (Smith et al., 2020). This study was conducted under different aging and combustion conditions using a tube furnace and indoor smog chamber. Optical properties were measured for $\mathrm{BB}$ aerosols produced under smoldering and flaming conditions for each fuel type. For each combustion condition, we reported the measured optical properties. These include scattering and extinction cross sections, single-scattering albedo (SSA), absorption and extinction for fresh emissions, emissions aged in the dark, and emissions photochemically aged in the absence of added volatile organic compounds (VOCs) as well as with VOCs added to represent urban emissions from a representative African megacity. In this part of the paper, we report the chemical composition of fresh and BB aerosols photochemically aged in the presence of VOCs, which were combusted at two different temperatures and collected onto filters.

Identifying the light-absorbing chromophores and nonabsorbing aerosol constituents by chemically characterizing $\mathrm{BrC}$ is a challenging task (Lin et al., 2015b). In this Part 2 paper, ultra-performance liquid chromatography (UPLC) was interfaced to both photodiode array spectrophotome- 
try (or DAD) and high-resolution quadrupole time-of-flight mass spectrometry (HR-QTOFMS) to chemically characterize BrC chromophores at the molecular level for both fresh and aged emissions; it is compared with similar measurements for BC. This technique (i.e., UPLC/DAD-ESI-HRQTOFMS) has previously been used for the molecular-level characterization of $\mathrm{BrC}$ constituents in laboratory-generated SOA (Lin et al., 2014, 2015a, 2016) and in ambient aerosols and cloud water impacted by BB (Kitanovski et al., 2012b; Budisulistiorini et al., 2017; Zhang et al., 2013).

\section{Experimental methods}

In the companion paper Part 1 (Smith et al., 2020), we described the aerosol generation and combustion system, the smog chamber characteristics, and the aging conditions and process. A summary is provided here. For laboratory samples, BB aerosols were generated by combusting $0.5 \mathrm{~g}$ of biomass samples in a tube furnace (Carbolite Gero, HST120300-120SN). Smoke and gases produced from combustion were sent directly into the smog chamber via a heated $\left(200^{\circ} \mathrm{C}\right) 1 / 4$ in. corrugated stainless-steel transfer tube. The North Carolina A \& T State University (NCAT) indoor smog chamber has a volume of $9.01 \mathrm{~m}^{3}$ and is lined with fluorinated ethylene propylene ethylene propylene (FEP) Teflon. Two sides of the chamber each have a bank of 32 ultraviolet (UV) lights (Sylvania, F30T8/350BL/ECO, 36" ), for a total of 64 lamps, to produce photochemical reactions. For the purposes of this experiment, a clean environment is maintained by flushing the smog chamber for at least $24 \mathrm{~h}$ with clean air coming from a clean air generator until negligible particle concentrations are reached.

The particle size distribution was continuously measured during the experiments. In general, it took about 15-20 min for the size distribution to become a Gaussian distribution. In addition, we checked the total mass concentration reported by the aerosol instrument manager software and confirmed that after 15-20 min of combustion the mass loading had become stable. We characterized this as a well-mixed condition in the chamber. An example of the size distribution for each fuel during an experiment is given in Fig. S1 in the Supplement.

For this study, authentic plant fuels were obtained from east Africa. These samples were weighed on a calibrated analytical balance so that it would approximately yield a total aerosol loading representative of a particular scenario (urban, wildfire, etc.). We utilized previously measured emission factors (Akagi et al., 2011; Simoneit, 2002; Yokelson et al., 2013; Andreae and Merlet, 2001), such as $18.5 \pm$ $4.1 \mathrm{~g} \mathrm{PM}_{10} \mathrm{~kg}^{-1}$ wood (dry weight) for tropical forest fuels (Akagi et al., 2011). For instance, to achieve a mass loading of $1100 \mu \mathrm{g} \mathrm{m}^{-3}$, which is the mean loading found in urban and suburban residential locations (Oyem and Igbafe, 2010), $0.5 \mathrm{~g}$ of wood was burned in these experiments. As deter- mined by scanning mobility particle sizer (SMPS) spectra and assuming a particle density of $1 \mathrm{~g} \mathrm{~cm}^{-3}$, typical peak particle concentrations were $800-900 \mu^{-3} \mathrm{~m}^{-3}$ for combustion at $500^{\circ} \mathrm{C}$ and $\sim 80 \mu \mathrm{g} \mathrm{m}^{-3}$ for combustion at $800^{\circ} \mathrm{C}$. Since aerosol densities are generally larger than $1 \mathrm{~g} \mathrm{~cm}^{-3}$, our estimated mass represents the lower limit of the actual values.

Optical measurements were performed after the chamber was mixed, since they could not be taken directly from the furnace given the long measurement time and high particle concentrations. While several types of aging were performed in Part 1, the work presented here focuses on photochemical aging with anthropogenic VOCs, specifically benzene, toluene, and xylene. No other atmospherically active species were added, such as $\mathrm{HONO}, \mathrm{NO}_{x}$, or $\mathrm{O}_{3}$, aside from those produced during combustion or resulting from photochemical aging. VOCs were injected into the chamber just before combustion while the UV lights were turned off, followed by $12 \mathrm{~h}$ of irradiation. While this is somewhat long for a chamber experiment, this length of time would represent a maximum change upon photochemical aging. Details of VOC addition are discussed in the first part of this paper (Smith et al., 2020). The purpose of adding the VOCs was to represent a polluted urban environment, for which we used the emission inventory for urban environments from South Africa. This does not necessarily represent the east African emission inventory, but this serves as a baseline since it represents the only data available to us for the continent Anthropogenic VOC concentrations were based on observations from several urban sites that were in the South African Air Quality Information System (SAAQIS). Average values for mid-July, the middle of the peak burning season for South Africa for the year 2016, were $\sim 1.25,3.5$, and $1.5 \mathrm{ppm}$ for benzene, toluene, and xylene, respectively. While these ratios were maintained in this chamber work, amounts introduced into the chamber were $\sim 12$ times more concentrated $(15,42$, and $18 \mathrm{ppm}$, respectively) due to sample preparation constraints, since the amounts needed for an exact match were too small to weigh accurately. In previous work, the total particle volume concentration $\left(\mathrm{nm}^{3} \mathrm{~cm}^{-3}\right)$ was found to undergo a first-order decay (Smith et al., 2019). The loss rate constant for this process was $(1.34 \pm 0.02) \times 10^{-3} \mathrm{~min}^{-1}$, which corresponds to a lifetime of $12.4 \mathrm{~h}$, so these samples underwent approximately one lifetime of particle losses. The chamber relative humidity was $0 \%$ or under the detection limit of the measurement device. Chamber temperature was 20-23 ${ }^{\circ} \mathrm{C}$, depending on the temperature of the room. The temporal evolution of chamber temperature and other characteristics have been extensively investigated for the NCAT indoor smog chamber (Smith et al., 2019).

\subsection{Fuel types and condition}

Eucalyptus, acacia, and olive have many things in common besides their wide distribution of growth. All are angiosperms and eudicots. Acacia and eucalyptus are more 
closely related, with both belonging to the rosid clade, while olive is an astrid. This is where their evolutionary similarities end, with acacia, eucalyptus, and olive in the orders Fabale, Myrtale, and Oleaceae, respectively. The common names of these species, followed by their botanical author citation, are eucalyptus (L'Hér), acacia (Mart.), and olive (L.). The fuel moisture content was $10 \%$. As such, there was minimal moisture content, and the fuels studied in this work are likely most relevant for situations in which these fuels are combusted in home heating and cooking or as the litter component of wildfires.

\subsection{Collection of filter samples}

BB aerosols were collected onto $47 \mathrm{~mm}$ Teflon filters (Tisch Environmental, SF18040) for chemical analysis and transmission electron microscope (TEM) grids (Ted Pella, 01844, carbon film on 400-mesh copper) for image analysis. For fresh BB aerosol, these samples were collected inline immediately after the furnace, only allowing enough distance from the furnace for the sample to cool before reaching the filters. This allowed fresh samples to be collected as close to the initial combustion as possible. The flow of the aerosol through the Teflon filter was driven by the chamber instrumentation, specifically the $\mathrm{CO}$ and $\mathrm{CO}_{2}$ analyzers, at $\sim 2.5 \mathrm{~L} \mathrm{~min}^{-1}$, while flow through the TEM grid was provided by a modified aquarium pump at $0.5 \mathrm{~L} \mathrm{~min}^{-1}$. With the output from the furnace at $10 \mathrm{~L} \mathrm{~min}^{-1}$, pressure was maintained through the system by diverting the excess flow $\left(7 \mathrm{~L} \mathrm{~min}^{-1}\right)$ to the exhaust. Samples were collected for the duration of the burn, which was typically around $10 \mathrm{~min}$. In this manner, approximately $25 \%$ and $5 \%$ of the total BB aerosol were collected onto the Teflon filter and TEM grid, respectively, after losses in the tube furnace and transfer tubing.

For aged BB aerosol, samples were taken directly from the chamber. Since the aerosol had already been diluted in the chamber, a larger sample volume was necessary for deposition onto the filters. For these samples, aerosol was taken from one of the chamber outputs, with a combined flow of $5 \mathrm{~L} \mathrm{~min}^{-1}$ through the Teflon filter and TEM grid setup produced by a separate pump. Samples were collected for $18 \mathrm{~min}$, which corresponded to $90 \mathrm{~L}$ of chamber air or $\sim 1 \%$ of the total chamber volume. With aged filter samples taken after approximately $24 \mathrm{~h}$ in the chamber, the particle concentration had been significantly reduced since initial combustion due to particle loss and dilution. However, the resulting samples were still large enough to be seen by the naked eye on the filter paper. Unused filters underwent the same extraction process as the sample filters to serve as a blank sample.

We estimated the approximate mass loading in the chamber during each combustion case by converting the SMPS size distribution into the total mass by assuming a density of $1 \mathrm{~g} \mathrm{~cm}^{-3}$. Our estimated mass represents the lower limit of the actual values. During the $500^{\circ} \mathrm{C}$ combustion cases, the typical concentration of aerosol after being well mixed was about $800 \mu \mathrm{g} \mathrm{m}^{-3}$, while that of the $800^{\circ} \mathrm{C}$ cases was about $100 \mu \mathrm{g} \mathrm{m}^{-3}$. After 12 to $15 \mathrm{~h}$ of aging, the initial mass loading was reduced by a factor of 2 , with a resulting concentration of about 400 and $50 \mathrm{\mu g} \mathrm{m}^{-3}$ during the 500 and $800{ }^{\circ} \mathrm{C}$ combustion cases, respectively.

\subsection{UPLC/DAD-ESI-HR-QTOFMS}

An Agilent 1200 Series UPLC system interfaced to a 6520 Series Accurate Mass Q-TOFMS instrument (Agilent Technologies, Santa Clara, CA) equipped with an ESI source (Lin et al., 2014) was operated in negative ion mode to chemically characterize BB organic aerosol (BBOA) constituents in filter samples collected from the tube furnace for fresh emissions and from the smog chamber for aged experiments. In brief, chromatographic separations were carried out using a Waters ACQUITY UPLC HSS T3 $\mathrm{C}_{18}$ column $(2.1 \times 100 \mathrm{~mm}, 1.7 \mu \mathrm{m}$ particle size; Waters Corporation, Milford, MA) at $45^{\circ} \mathrm{C}$. The mobile phases consisted of eluent (A) $0.1 \%$ acetic acid in ultrapure water $(>18 \mathrm{M} \Omega \mathrm{cm})$ and eluent (B) $0.1 \%$ acetic acid in pure methanol $(99.9 \%$, Fisher Chemical). The gradient elution program was as follows: eluent (A) held at $100 \%$ from 0 to 2 min, decreased linearly to $10 \%$ from 2 to $10 \mathrm{~min}$, held constant at $10 \%$ between 10 and $11 \mathrm{~min}$, increased linearly to $100 \%$ from 11 to $15 \mathrm{~min}$, and held constant at $100 \%$ during a 5 min post-run for column reequilibration. The sample injection volume was $5 \mu \mathrm{L}$ at a flow rate of $0.3 \mathrm{~mL} \mathrm{~min}^{-1}$. A diode array detector (DAD) between the UPLC system and the mass spectrometer was operated to measure UV-visible (UV-vis) absorbance from 200 to $800 \mathrm{~nm}$ with a step of $2 \mathrm{~nm}$. At the beginning of each analysis period, the mass axis of the Q-TOFMS was calibrated using a commercially available ESI-L low-mass tuning mixture (Agilent Technologies, Santa Clara, CA) containing seven masses ranging from 60 to $1700 \mathrm{Da}$. For real-time mass correction, a solution containing three reference mass components was continuously infused for real-time mass axis correction (calibration). The resultant mass resolution of the ESI-HR-QTOFMS over $m / z 60-1700$ ranged from $\sim 11000$ at the low-mass end to $\sim 17000$ at the high-mass end. Raw data were acquired and processed with MassHunter software (version B.06.00, build 6.0.633.0; Agilent Technologies, Santa Clara, CA).

\subsection{Sample preparation and $\mathrm{BrC}$ identification}

Filter samples collected as described in the last section were extracted individually in $22 \mathrm{~mL}$ of pure methanol by sonication for $45 \mathrm{~min}$, blown dry under a gentle nitrogen stream at room temperature $\left(21-22^{\circ} \mathrm{C}\right)$, and reconstituted in $300 \mu \mathrm{L}$ of $50: 50(\mathrm{v} / \mathrm{v})$ methanol / water solvent mixture for the subsequent UPLC/DAD-ESI-HR-QTOFMS analysis. While the water-soluble fraction of $\mathrm{BrC}$ is less than $70 \%$, almost $90 \%$ of $\mathrm{BrC}$ can be extracted by organic solvents, such as methanol. Furthermore, the water-insoluble fraction of $\mathrm{BrC}$ 
is more absorbing than the water-soluble fraction (Lin et al., 2017; Bergstrom et al., 2007; Laskin et al., 2018). Immediately prior to analysis, each reconstituted extract was filtered through a polytetrafluoroethylene (PTFE) syringe filter (Agilent, $0.2 \mu \mathrm{m}$ pore size) to remove undissolved particles such as soot components. A similar procedure was used by other research studies (Kumar et al., 2018; Jiang et al., 2019).

Previous work went into quantifying $\mathrm{BrC}$ aerosol constituents identified by UPLC/DAD-ESI-HR-QTOFMS; seven external (2-nitrophenol, 4-nitro-1-naphthol, 4-methyl5-nitrocatechol, vanillin, vanillic acid, coniferaldehyde, and benzoic acid) commercially available authentic standards were prepared for six-point calibration curves from 0.004 to $10 \mu \mathrm{g} \mathrm{mL}^{-1}$, with detection limits below $0.004 \mu \mathrm{g} \mathrm{mL}^{-1}$. While several of these methods were used in this work, determining the absolute quantity of a BrC constituent was not pursued. From the previous tests of quality control, the recovery rate of ketopinic acid was $\sim 90 \%$ among $20 \mathrm{BB}$ aerosol samples with the same extraction process with methanol and the UPLC/DAD-ESI-HR-QTOFMS method. Two filter samples (with the collected $\mathrm{PM}_{2.5}$ masses $>1 \mathrm{mg}$ ) were reextracted using $70: 30(\mathrm{v} / \mathrm{v})$ acetonitrile / toluene solvent mixture. Most of the identified $\mathrm{BrC}$ species were below the detection limit from this second extraction, suggesting excellent extraction efficiency for the first time with methanol. Only a few BrC aerosol constituents (e.g., vanillic acid, coniferaldehyde) were detected from the second extraction, but their abundance was lower than $1.5 \%$ of that from the first extraction. The only exception was 2-nitrophenol, whose extraction efficiency using methanol was $\sim 55 \%$ for the first time.

\subsection{Non-targeted analysis}

Non-targeted MS analyses were performed to compare the filter samples collected from the smog chamber experiments under different conditions, such as fuel type, combustion temperature, and aging, to reveal the major molecular secondary BBOA products, with a focus on BrC. The raw data files acquired from UPLC/ESI-HR-QTOFMS were first transformed into ".mzData" format by Agilent MassHunter and then processed by the online metabolomics platform XCMS (https://xcmsonline.scripps.edu/, 26 September 2009) (Tautenhahn et al., 2012). During this transformation, only peaks that had intensities above $0.6 \%$ of the base peak were selected. Workflow parameters were adopted from previous work with modifications (Tian et al., 2017). In brief, the "centWave" algorithm was used for peak detection, with a peak width range of 5-60 s, and the mass error tolerance was set at $20 \mathrm{ppm}$. Peak alignment required an $m / z$ width (mzwid) at 0.025 . Generally, around 30 major BBOA constituents were filtered out by XCMS and were then examined in MassHunter to make sure they possessed good peak shapes and were not present in the filter blank samples. The resulting blank and sample chromatograms are presented in Fig. S2.

The following data fields were used for each compound returned by the XCMS platform: median $\mathrm{m} / \mathrm{z}$ ratio, median retention time (RT), and the intensities for each sample in the pairwise comparison. Compounds with a similar $m / z$ ratio, regardless of observed retention times, had their relative intensities combined, as they most likely returned the same chemical formula. Later, for relatively large peaks with slightly different median $m / z$ values, when species were found to have the same molecular formula as determined by MassHunter (see below), their ion intensities were also combined. The amount of aerosol varies significantly from sample to sample, especially between fresh filter samples collected directly from the furnace during combustion and aged filter samples collected from the chamber, with the former always being much greater. Due to the lack of authentic standards for quantifying individual BBOA, these masses were not determined at the time of their collection, and their spectral intensities could not be normalized to a specific aerosol mass or tracer for aerosol mass. As such, no direct comparison between samples could be made without first normalizing spectra. We normalized the intensity data by generating a scaled intensity difference between the samples using the following equation:

$$
\frac{x_{1}}{\sum x_{1, i}}-\frac{x_{2}}{\sum x_{2, i}}
$$

where $x_{1}$ is the intensity from the first sample, $x_{2}$ is the intensity from the second sample, and each term represents the fractional integrated ion intensity of their respective samples. Positive values indicate that a compound was more abundant in the first sample, while negative values indicate that a compound was more abundant in the second sample. The results of the XCMS platform were then sorted to exclude any absolute scaled intensity differences less than $0.5 \%$, which left around 30 compounds or fewer to identify for each pairwise comparison.

The MassHunter software was then used to confirm and identify the compounds found by the XCMS platform. For each pairwise comparison, extracted-ion chromatograms (EICs) were generated for both samples and any relevant blank samples for each of the $m / z$ ratios found by XCMS. MS results were then generated from any peaks found in the EICs. MassHunter's built-in formula generator was used to identify the most likely compounds associated with the $m / z$ ratio and retention time identified by XCMS. These chemical formulas, along with their double bond equivalent (DBE), mass difference, and number of chromatographic peaks (at different retention times, most likely isomers of the compound) were cataloged with updated $m / z$ ratios and retention times as identified by MassHunter. Lastly, suggested identities were assigned to each chemical formula based on the relevant literature. Any compounds that were 
also found in the blank sample(s) were removed from the catalog.

\subsection{UV-visible analysis}

The UV-visible spectra in this work were not generated for specific molecular species but for all molecular species that were extracted and chromatographically and spectroscopically measured. Spectra were derived by integrating across the entire chromatogram within MassHunter. Each was background-subtracted from a blank run, though the resulting spectra could not be compared directly because of the reasons mentioned earlier. Since some negative absorption values were produced after background subtraction, baseline values were shifted such that the smallest absorption intensity above $250 \mathrm{~nm}$ was made barely positive (by $0.00001 \mathrm{mAU}$ ), and all values were divided by the spectral maximum to produce a peak value of 1 in the 250 $800 \mathrm{~nm}$ range. The reason all values were made slightly positive was that it enabled the determination of a normalized Angstrom absorption exponent (NAAE). Because the baseline was shifted to allow for a log plot, this is mathematically different than the AAE and should only be used for comparison purposes. With a focus on the $500-570 \mathrm{~nm}$ region, the NAAE and the normalized slope vs. wavelength were determined. Heat map chromatograms of absorption vs. wavelength and retention time are given in Fig. S3.

\section{Results and discussion}

\subsection{MS analysis of fresh emissions}

Because the chemical measurements of the BB aerosols derived from acacia and eucalyptus fuels were the most robustly sampled in this work, a comparison of those results is presented here, though a few references to olive will be made. Figure 1 shows the UPLC/ESI-HR-QTOFMS negative-ionmode difference spectra produced for these BB aerosol types. Peaks that are positive are more abundant in the acaciaderived BB aerosol sample, while negative peaks are more present in the eucalyptus-derived BB aerosol sample. Table 1 highlights the molecular differences between the BB aerosols derived from freshly combusted acacia and eucalyptus fuels, showing the scaled intensity difference for species with an absolute difference greater than $0.5 \%$, the mean peak $m / z$, the mass difference between the measured and the monoisotopic mass of the formula determined using MassHunter (listed here as a measure of formula identification quality), the determined formula, the double bond equivalence (DBE) of the formula, the number of chromatographic peaks seen from an EIC, and the suggested identity based on the formula and relevant literature.

Except for dihydroxyphthalic acid and other tentatively assigned compounds, there is very little difference between the two fuel types when they are combusted at $800^{\circ} \mathrm{C}$. This is consistent with previous work, wherein flaming combustion leads to the formation of predominantly BC aerosol (Reid et al., 2005). The modified combustion efficiencies (MCEs), discussed in companion paper (Part 1), were $0.974 \pm 0.015$ when averaged from 12 different burns performed at $800^{\circ} \mathrm{C}$, which supports the idea that these aerosols represent particles that were emitted during the flaming stage of combustion that is dominated by $\mathrm{BC}$ aerosol. Since most of the chemical differences between samples are very small, this suggests that either very few $\mathrm{BrC}$ species are produced for either fuel, or there are numerous species that are essentially the same between the samples. In Part 1, eucalyptus was shown to have a higher SSA, $\sim 0.43$ for $300 \mathrm{~nm}$ particles, than acacia, which is more absorbing and has an SSA of $\sim 0.3$ at that size (see Figs. 3 and 4 in Part 1). This would suggest that eucalyptus has more non-absorbing OA or is at least less absorbing than BC. It is unlikely that dihydroxyphthalic acid would produce a significant, but wavelength-dependent, absorption in the 500-570 nm region of the spectrum. Conversely, it is acacia that appears to have many more low-abundant organic constituents. This suggests one or more of the following: (1) that eucalyptus has significantly more complex combustion products than acacia such that their abundances fall below the lower threshold of XCMS analysis; (2) that eucalyptus combustion products are either unresponsive in the negative ion mode of the UPLC/ESI-HR-QTOFMS analysis, such as having very high molecular weights (MWs), which prevents them from eluting off the UPLC column or having no acidic functionalities; (3) that those products are not extractable by methanol; (4) that those products are semivolatile and were removed during the offline sample processing for UPLC/DAD-ESI-HR-QTOFMS analyses; and/or (5) that differences between the observed SSA values are due to morphology differences. Very high-MW compounds, such as polycyclic aromatic hydrocarbons (PAHs), are potentially present, but it is unlikely that such large molecules would lack the ability to absorb light (see Sect. 3.3) to produce more scattering aerosol for eucalyptus, thus discounting part of reason (2). Negative-ion-mode ESI is known to bias detection in favor of acidic compounds, such as those with carboxylic acids, nitro-aromatics, sulfated organics, and those that have sufficiently acidic $-\mathrm{OH}$ groups. Given that lightabsorbing OA seems significantly soluble in methanol $(\mathrm{Ku}-$ mar et al., 2018), reason (3) is also unlikely. If one assumes that XCMS is capturing the complexity of molecular species, it is likely that eucalyptus products are low-MW species that are semi-volatile, that those low-MW species are not captured by UPLC/DAD-ESI-HR-QTOFMS analyses, that the observed differences in SSA are due to morphology differences, or a combination of the three. One potential explanation would be a compound such as eucalyptol (1,8-cineole), which is a large fraction of eucalyptus oil, that is a cyclic ether that lacks any basic functionality, has good solubility in alcohols, and does not absorb in the UV and visible. When extracting essential oil from eucalyptus leaves by water- 

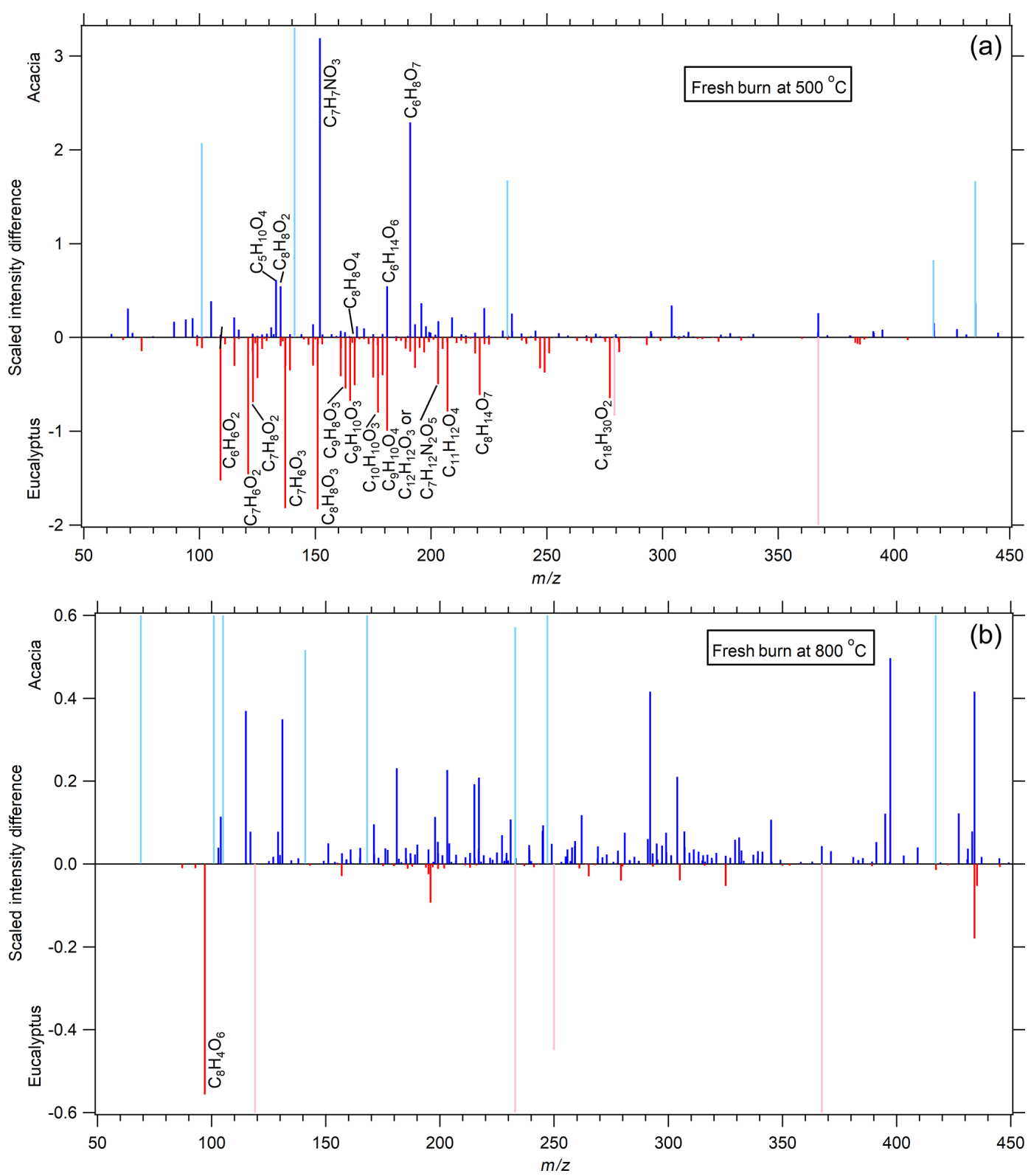

Figure 1. A comparison of fresh acacia and eucalyptus fuels combusted at $500{ }^{\circ} \mathrm{C}$ (a) and $800{ }^{\circ} \mathrm{C}$ (b) in terms of the scaled intensity difference (see Sect. 2.5). Species more present in acacia-derived BB aerosols have positive values (blue lines), while those more present in eucalyptus-derived BB aerosols have negative values (red lines). Peaks in lighter colors were present in the XCMS analysis but were found to be present in significant amounts in the blank sample. Many of these peaks that were found in the blank extend past the scale of the plot but were cut off to focus on species associated with BB aerosol. Compounds having an absolute difference greater than $0.5 \%$ have been labeled. Far more differences are revealed at the lower-temperature burn, and different classes of compounds are expressed in different relative amounts for acacia and eucalyptus combustion.

steam distillation, an oil yield of $0.3 \%-2.0 \%$ (dry weight) was produced, of which 7\%-75\% was eucalyptol, depending on the species (Masamba et al., 2001; Subramanian et al., 2012). The presence of such a compound should be apparent under positive-ion-mode ESI, atmospheric pressure chemical ionization MS analysis, and possibly FT-IR if present in sufficient quantities.
Combustion of each fuel at $500{ }^{\circ} \mathrm{C}$ presents a very different picture, not only because of the number of species differentiated by their mass, but also the number of isomers present for each mass. The number of chromatographic peaks in the EICs is listed for each mass in Table 1. In that table, all species are present in both samples to differing degrees, except for octadecatrienoic acid, which is likely linolenic acid 


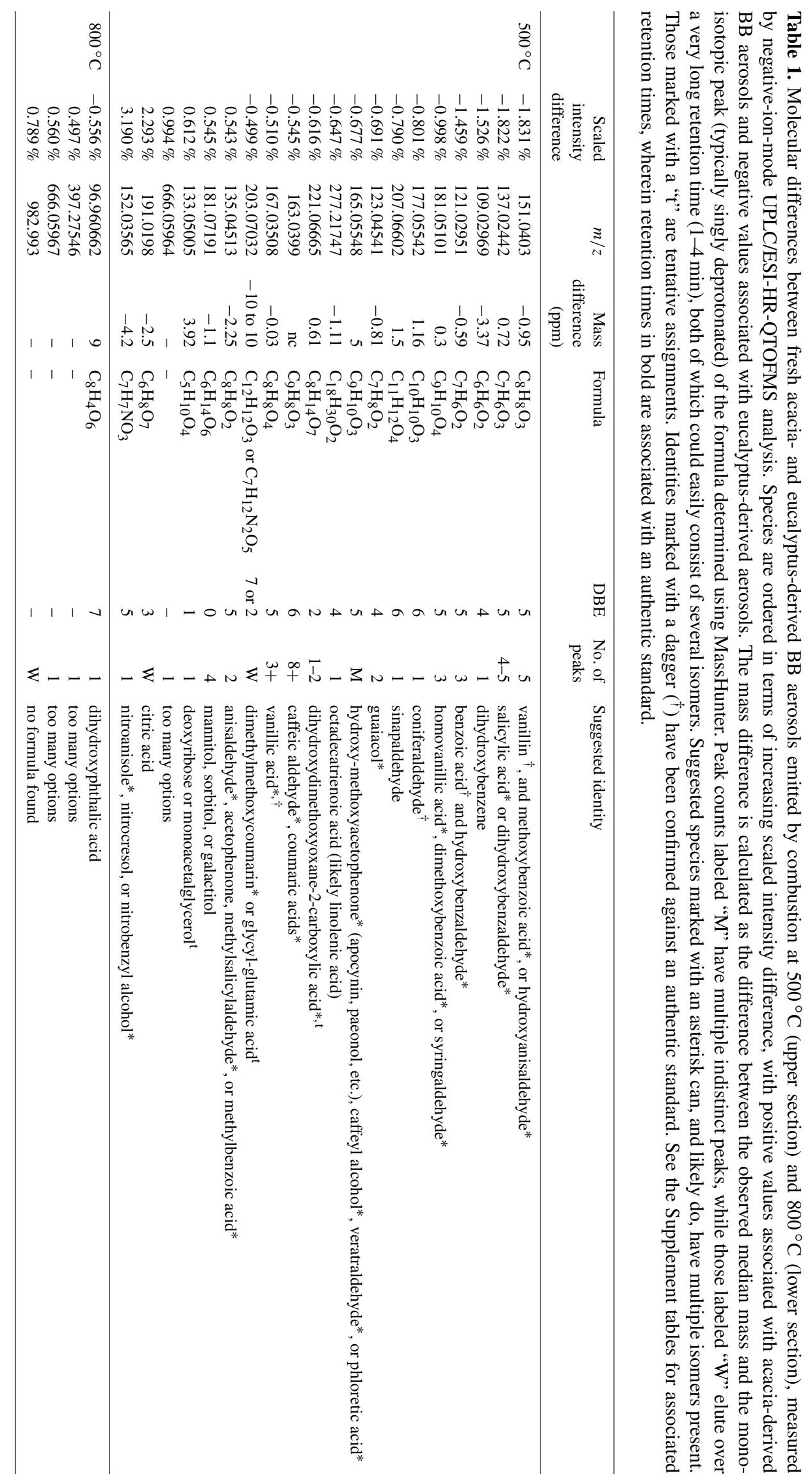


and is only present in eucalyptus. To demonstrate this complexity, $m / z 151.04$ was vanillin (a hydroxy methoxy benzaldehyde confirmed with an authentic standard) (Budisulistiorini et al., 2017), hydroxyanisaldehyde, and/or methoxybenzoic acid (such as anisic acid), but it consists of five isomers, likely differing in the placement of functional groups along the aromatic ring. These are previously observed lignin pyrolysis products (Simoneit, 2002) that are more prevalent in eucalyptus. This includes only one isomer of dihydroxybenzene, which is likely catechol (Simoneit, 2002), though resorcinol is also possible, since it has been observed in gas-phase measurements of prescribed fires (Yokelson et al., 2013). At least four isomers of hydroxybenzoic acid, such as salicylic acid and/or dihydroxybenzaldehyde, are present and more abundant in eucalyptus. While these compounds have the same structural motifs as other lignin pyrolysis products, only salicylic acid (Fleming et al., 2020) and 4hydroxybenzoic acid (Bi et al., 2008) have been previously observed as $\mathrm{BrC}$ chromophores associated with $\mathrm{BB}$, which suggests that there are at least two other unidentified isomers. Other lignin pyrolysis products are noticeably more abundant for eucalyptus combustion at $500{ }^{\circ} \mathrm{C}$ and are likely the following: BrC chromophores, such as benzoic acid (confirmed by an authentic standard), and two isomers of hydroxybenzaldehyde at $\mathrm{m} / \mathrm{z}$ 121; homovanillic acid, dimethoxybenzoic acid, and/or syringaldhyde (three isomers observed) at $\mathrm{m} / z 181$ (Simoneit, 2002); coniferaldehyde at $\mathrm{m} / z 177$ (confirmed); sinapaldehyde (and not another isomer) at $m / z 207$ (Fleming et al., 2020); guaiacol and some other isomer at $m / z$ 123; and the ubiquitous vanillic acid at $m / z 167$ (confirmed) (Fleming et al., 2020; Simoneit, 2002). Distillation products more prevalent in eucalyptus include an indistinct number of isomers of hydroxy-methoxyacetophenone (e.g., apocynin or paeonol), caffeyl alcohol, and/or phloretic acid at $m / z$ 165. The last distillation product expressed more in eucalyptus is at least one isomer of what is likely dimethyl methoxycoumarin. These species have been observed previously as a class of compounds (Fleming et al., 2020; Lin et al., 2016), though not this one particularly to the authors' knowledge. At least eight isomers of caffeic aldehyde, veratraldehyde, and/or coumaric acid are also present.

Other species are present in greater abundance in acacia at $500{ }^{\circ} \mathrm{C}$. Saccharides such as mannitol and sorbitol have been observed as pyrolysis products of cellulose and in road dust (Simoneit et al., 2004), though two more isomers, one likely being galactitol $\left(\mathrm{C}_{6} \mathrm{H}_{14} \mathrm{O}_{6}\right)$, are also present. Similarly, citric acid has been observed as a product from saccharide combustion (Bi et al., 2008), though the authors have not been able to find references to deoxyribose or monoacetalglycerol in the literature. Nitro-aromatic species have been shown to be produced during the pyrolysis process from fresh combustion in this work, wherein one isomer of nitroanisole, nitrocresol, or nitrobenxyl alcohol is present and produced in significantly higher quantities in acacia than eucalyptus.
Work by Fleming et al. (2020) shows that sinapaldehyde and coniferaldehyde are two known lignin pyrolysis products that are produced from their corresponding lignin monomeric units, specifically sinapyl and coniferyl alcohol. They also state that these species are anticorrelated; sinapaldehyde is more prevalent in angiosperms and flowering fuels, while coniferaldehyde is more abundant in conifers and softwoods. We examined our BBOA mass spectra for sinapaldehyde $\left(\mathrm{C}_{11} \mathrm{H}_{12} \mathrm{O}_{4},[\mathrm{M}-\mathrm{H}]=207.0657\right)$ and coniferaldehyde $\left(\mathrm{C}_{10} \mathrm{H}_{10} \mathrm{O}_{3},[\mathrm{M}-\mathrm{H}]=177.0552\right)$ and found that both had a single peak with a co-eluting retention time of $\sim 9.2 \mathrm{~min}$. Additionally, both species were found in all three fuels eucalyptus, acacia, and olive. When integrating the chromatogram between 9.0 and $9.5 \mathrm{~min}$ and extracting the resulting mass spectrum, a comparison of relative ion intensities was made. The coniferaldehyde / sinapaldehyde ratio was found to be 1.6, 3.4, and 2.6 for eucalyptus, acacia, and olive, respectively. In contrast to Fleming et al. (2020), we found that all of these species (all angiosperms) had a consistently higher amount of confieraldehyde than sinapaldehyde, though this ratio varied by about a factor of 2 between species studied here. One possible reason for this was that Fleming et al. (2020) reported their results in terms of absorption intensity and not ion intensity. Since these species co-eluted during our separation, it was not possible to distinguish them on that basis.

According to the above analysis, there should be more, and more varied, species present in eucalyptus than acacia. The main species present in greater abundances in acacia are derived from sugars and cellulose and are not chromophores. In Part 1 of this work, we found that acacia has a higher SSA than eucalyptus when combusted at $500{ }^{\circ} \mathrm{C}$, by $0.1-0.2$, depending on particle size. This suggests that either acacia has larger absolute amounts of non-chromophore compounds or eucalyptus has a greater quantity of chromophores whose absorptive properties extend to the $500-570 \mathrm{~nm}$ region of the visible spectrum. This will be discussed in further depth when relating MS results to UV-visible absorption results in Sect. 3.3.

\subsection{MS analysis of aging effects}

Figure 2 is similar to Fig. 1, but rather than contrasting different species, a single species, eucalyptus, is differentiated in terms of the aging process. Peaks with positive values indicate those that are more present in the fresh sample, while those with negative values are more present in the aged one. Another way to interpret this is that those with positive values are no longer present in the aged sample because they have been chemically changed due to the aging process. Those with negative values are either being produced by the aging process or are durable enough to be more significant, in a relative sense, in the aged sample. Again, we have attempted to identify compounds that change by more than $0.5 \%$, indicating the molecular formula for those in Fig. 2 and listing 
them in Table 2 along with their suggested identities. Similarly, Fig. 3 and Table 3 show the results for fresh versus aged acacia.

At $800^{\circ} \mathrm{C}$, there appears to be very little occurring due to the aging process in the presence of UV light and VOCs. This suggests that there were very few $\mathrm{BrC}$ species to begin with and that the presence of anthropogenic VOCs did not significantly impact the chemical makeup of these aerosols. It is also possible that semi-volatile species produced during the oxidation of these VOCs were lost in significant quantities to the chamber walls rather than the particle phase. The only significant products of oxidation were dihydroxyphthalic acid, which is likely a product of xylene oxidation, and a mixture of caffeic aldehyde, veratraldehyde, and/or hydroxy cinnamic acid isomers, such as coumaric acid. Examining the SSA changes due to aging under either dark or UVilluminated conditions was not possible for the experimental reasons stated in Part 1.

Eucalyptus combusted at $500^{\circ} \mathrm{C}$ is far more complex. Since many of these compounds have been discussed in more depth earlier, this discussion will only focus on compounds that are distinctly different as a function of age or those not previously mentioned. Another distillation product, benzoic acid and the lignin pyrolysis product hydroxybenzaldehyde isomer (such as salicylaldehyde), likely underwent similar processing. Derivatives of the aromatic lactone coumarin are also known distillation products present in biomass burning (Fleming et al., 2020; Laskin et al., 2015). While not as prevalent as lignin pyrolysis products, a significant number do seem to be consumed due to UV irradiation and/or photochemistry. This includes species that were not distinctly different from acacia, as discussed earlier, such as seven isomers of methoxy- and/or methylhydroxycoumarin $\left(\mathrm{C}_{10} \mathrm{H}_{8} \mathrm{O}_{3},[\mathrm{M}-\mathrm{H}]=175.0402\right)$, neither of which have been previously observed to the authors' knowledge. Others include all six possible isomers of hydroxycoumarin $\left(\mathrm{C}_{9} \mathrm{H}_{6} \mathrm{O}_{3}\right.$, $[\mathrm{M}-\mathrm{H}=161.0241)$, of which umbelliferone has been previously observed (Fleming et al., 2020). There are also multiple indistinct peaks that can correspond to one of several hydroxy methoxyacetophenones (apocynin (acetovanillone), paeonol, etc.), caffeyl alcohol, and/or phloretic acid $\left(\mathrm{C}_{9} \mathrm{H}_{10} \mathrm{O}_{3},[\mathrm{M}-\mathrm{H}]=165.0556\right)$, many of which have been extracted from various plants but have not been observed as constituents of BBOA. There are four to five isomers of acetylanisole or, less likely, hydrocinnamic acid or tolyacetic acid. Octadecatrienoic acid has also been removed, likely by a reaction of one of its double bonds with ozone or the $\mathrm{OH}$ radical.

In comparison, the compounds being removed from eucalyptus combusted at $500{ }^{\circ} \mathrm{C}$ are dominated by lignin pyrolysis products. Most of these have already been discussed. One isomer of dihydroxybenzene, being either resorcinol or catechol, was a pyrolysis product and seems sensitive to the aging process, such as oxidation by $\mathrm{OH}$ or by bleaching, since it absorbs in the UV at $290 \mathrm{~nm}$ (Dewar et al., 1958). Both proper isomers of acetosyringone and/or homoveratic acid $\left(\mathrm{C}_{10} \mathrm{H}_{12} \mathrm{O}_{4},[\mathrm{M}-\mathrm{H}]=195.0664\right)$ have previously been observed (Simoneit, 2002) and may be present here, though it cannot be definitively stated that these specific isomers are present. Highlighting the smoldering conditions present during combustion at this temperature, there are two isomers of either anisyl alcohol, creosol, or some dimethoxybenzene compound $\left(\mathrm{C}_{8} \mathrm{H}_{10} \mathrm{O}_{2},[\mathrm{M}-\mathrm{H}]=137.0609\right)$. These are thought to be precursors of other more highly oxygenated pyrolysis products of lignin, such as anisic acid, vanillin, or vanillic acid (Simoneit, 2002). These have similar structural motifs as lignin products and they may be regarded as distillation products. There are only a few compounds produced because of aging, such as dihydroxyphthalic acid and a very high-MW compound identified as $\mathrm{C}_{39} \mathrm{H}_{74} \mathrm{~N}_{2} \mathrm{O}_{5}$, which may be a dinitro compound. As mentioned previously, dihydroxyphthalic acid could be a product of xylene oxidation, but no enhancement of OA was observed in Part 1 of this work when comparing aging under lights to lights with anthropogenic VOCs. While there is a slight increase in SSA due to the presence of VOCs, it would be difficult to point to this one compound as the sole difference. Lastly, there is dihydroxyanthracene, which is likely a secondary oxidation product of the PAH anthracene. This compound should absorb in the UV and visible, given the absorption of 1hydroxyanthracene from the UV to $\sim 410 \mathrm{~nm}$ (Tichy, 1967).

Figure 3 and Table 3 show the results from aged acacia. As before, very little has changed for the acacia fuel combusted at $800^{\circ} \mathrm{C}$. Combustion at $500{ }^{\circ} \mathrm{C}$ is far richer and consists almost exclusively of compounds that have been consumed (i.e., have a positive scaled intensity difference). The species undergoing the most significant loss is either resorcinol or catechol. The second most consumed compound, which was not seen previously, is one isomer that is either nitroanisole, nitrocresol, or possibly nitrobenzyl alcohol $\left(\mathrm{C}_{7} \mathrm{H}_{7} \mathrm{NO}_{3},[\mathrm{M}-\mathrm{H}]=152.0356\right)$. Given that it is being consumed over the course of the aging process, it was likely formed as a primary species during the combustion of lignin in the presence of $\mathrm{NO}_{x}$. While this species has not been observed previously, related compounds such as nitrocatechol and methyl nitrocatechol have (Fleming et al., 2020). Given that these compounds have absorption spectra that extend to $\sim 500 \mathrm{~nm}$, they were likely decomposed due to photobleaching, though heterogeneous reactions with $\mathrm{OH}$ cannot be ruled out. It is likely that the products of this photobleaching and/or oxidation were numerous, and each had an abundance that was too small to be captured in this analysis.

Given that one isomer of dihydroxybenzene undergoes the greatest change upon aging, it is worth examining potential chemical transformations further. While resorcinol is a potential identity, catechol has gained significant attention due to its involvement as a precursor to a strong chromatophore. Catechol can react in the atmosphere to form 4nitrocatechol $\left(\mathrm{C}_{6} \mathrm{H}_{5} \mathrm{NO}_{4}\right)$ through photochemical and dark processes in the gas and aqueous phase through several 


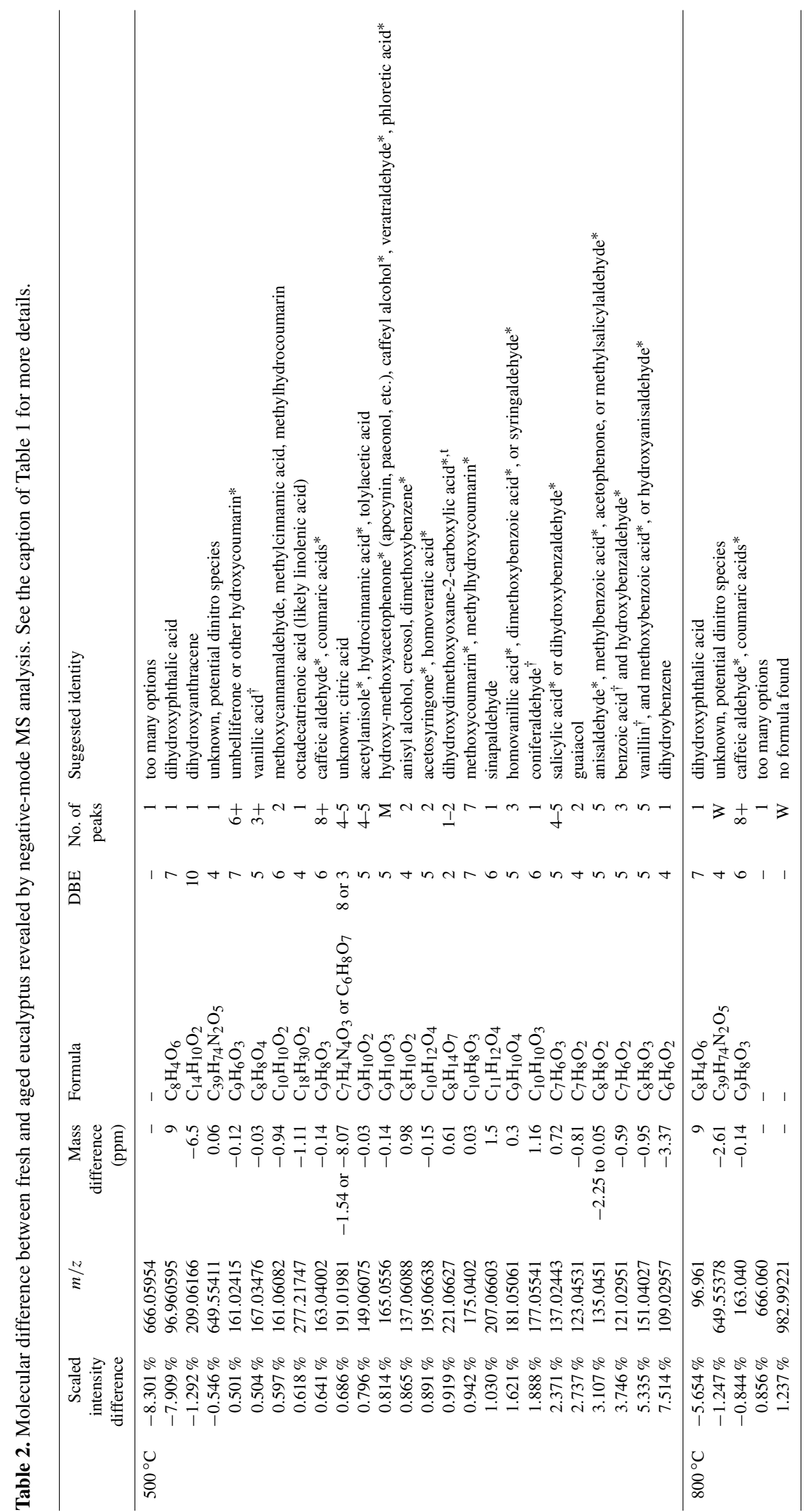




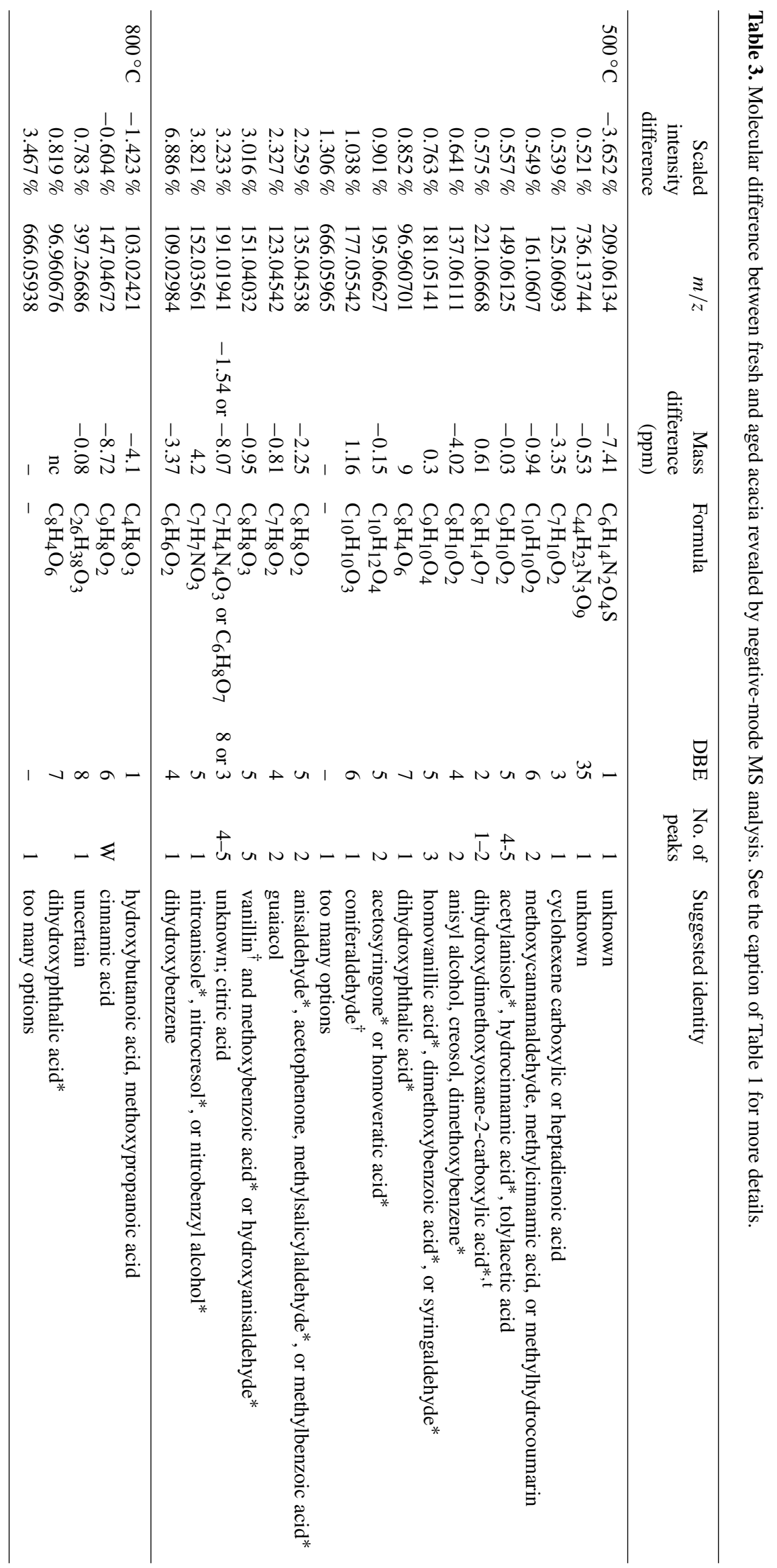



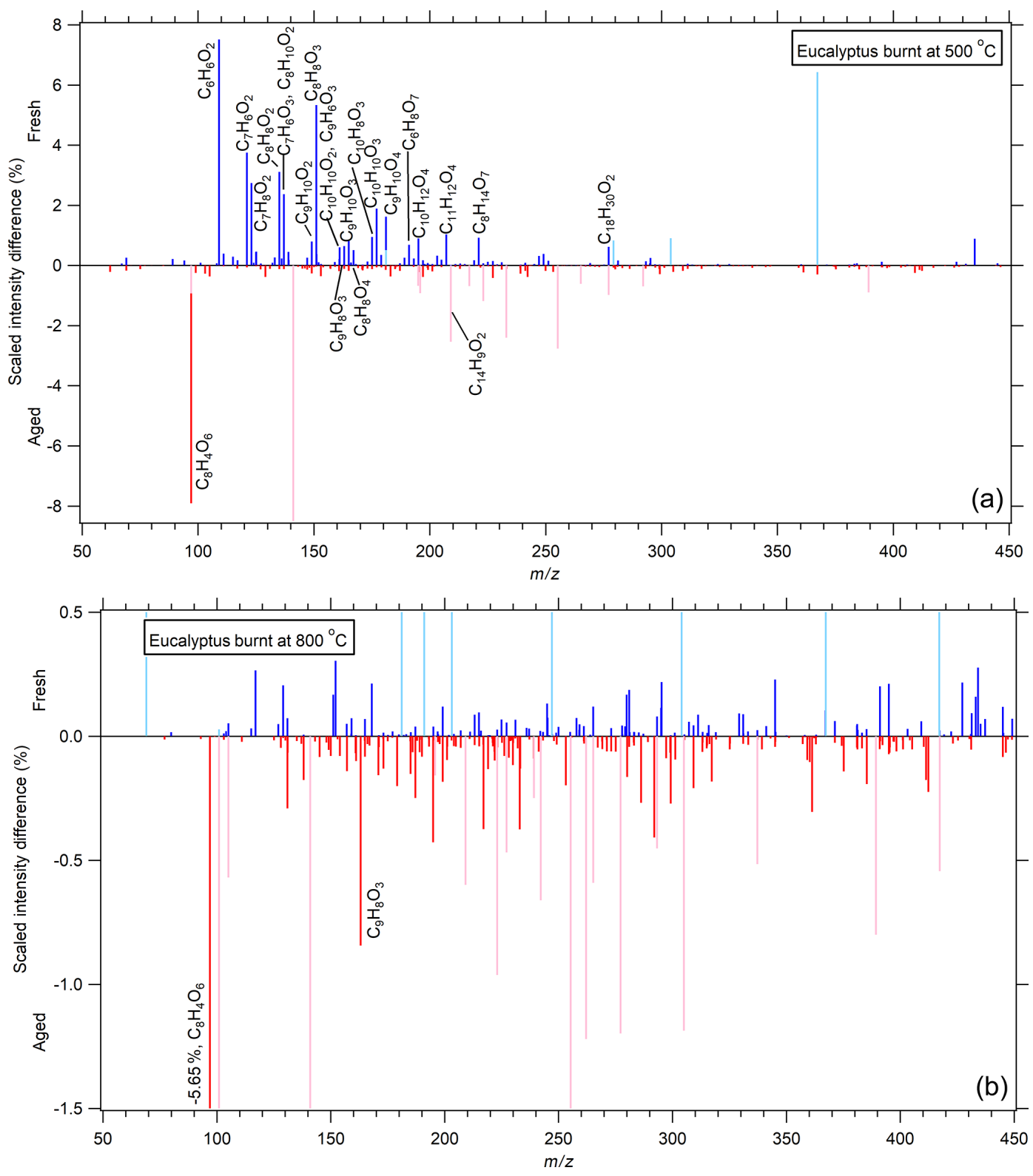

Figure 2. A comparison of eucalyptus-derived BB aerosol combusted at $500^{\circ} \mathrm{C}$ (a) and $800^{\circ} \mathrm{C}$ (b) under fresh and photochemically aged conditions with VOCs in terms of the scaled intensity difference (see Sect. 2.5). Species more present in the fresh sample have positive values (blue lines), while those more present in the aged sample have negative values (red lines) (i.e., species with positive values have been removed because of the aging process, while those with negative values are either produced or represent a greater relative contribution to the aged sample). Peaks in lighter colors were present in the XCMS analysis but were found to be present in significant amounts in the blank sample. Many of these peaks that were found in the blank extend past the scale of the plot but were cut off to focus on species associated with BB aerosol. Compounds having an absolute difference greater than $0.5 \%$ have been labeled. There is very little change for combustion at $800^{\circ} \mathrm{C}$, while $500^{\circ} \mathrm{C}$ shows a net removal of many compounds.

mechanisms (Finewax et al., 2018; Kroflič et al., 2018; Vidovic et al., 2018; Wang et al., 2019). Given the dryness of our chamber and the presence of UV irradiation, this mechanism would proceed through hydrogen abstraction from the hydroxyl by $\mathrm{OH}$ to produce a $\beta$-hydroxyphenoxy / $o$ semiquinone radical, followed by radical-radical combination with $\mathrm{NO}_{2}$ (Finewax et al., 2018). Both fresh and aged spectra for $500^{\circ} \mathrm{C}$ combustion were examined for nitrocatechol $\left((\mathrm{M}-\mathrm{H})^{-}\right.$at $m / z$ 154.0140), and it was found at an RT of 8.39-8.55 min in both fresh and aged acacia and eucalyptus. There was a greater abundance in the aged samples despite the mass loading on the filter being lower, suggesting a small amount from primary emission but mainly a product of secondary formation for both fuels. 

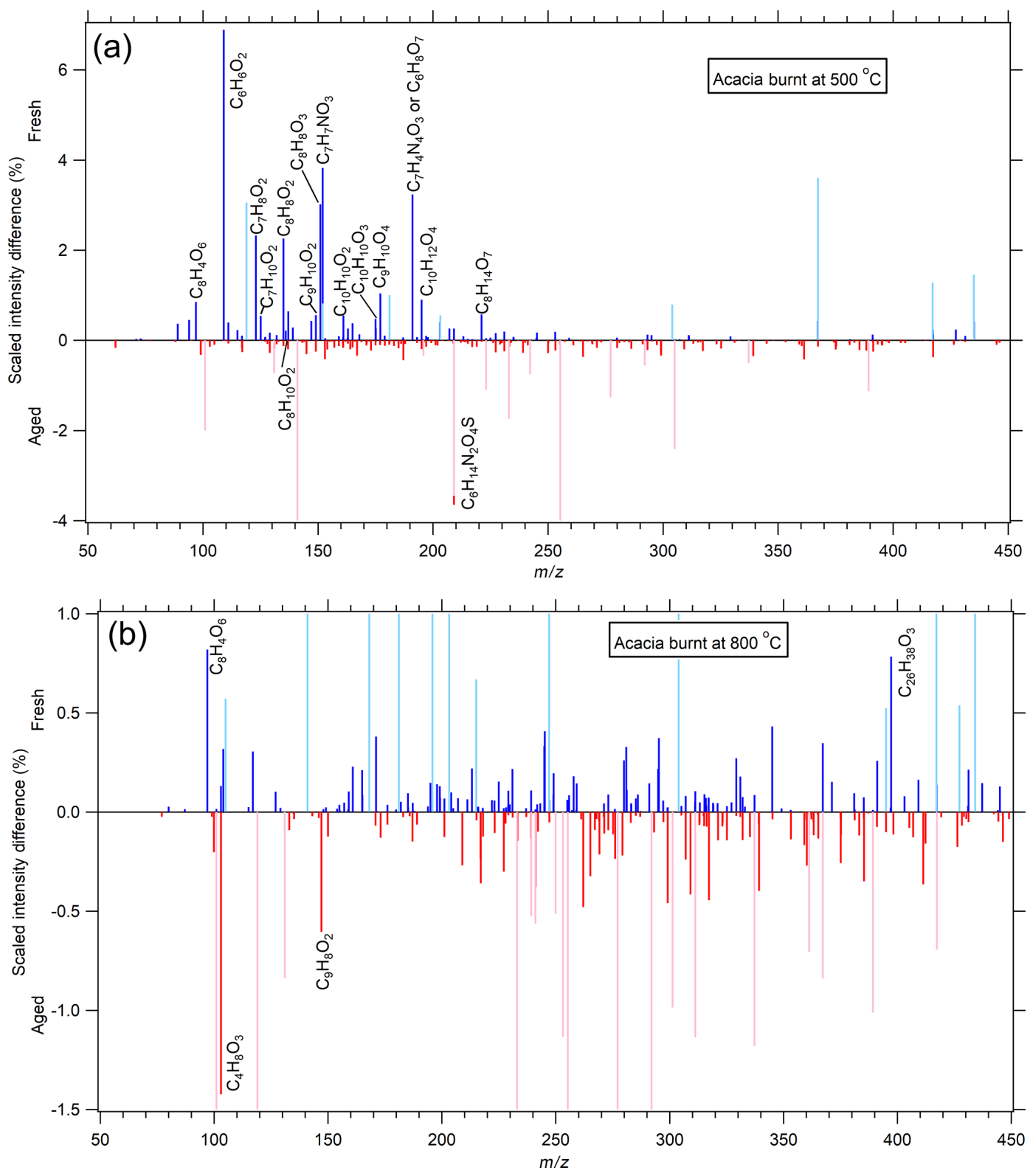

Figure 3. A comparison of acacia-derived $\mathrm{BB}$ aerosol combusted at $500^{\circ} \mathrm{C}$ (a) and $800^{\circ} \mathrm{C}$ (b) under fresh and photochemically aged conditions with VOCs in terms of the scaled intensity difference (see Sect. 2.5). Species more present in the fresh sample have positive values (blue lines), while those more present in the aged sample have negative values (red lines) (i.e., species with positive values have been removed because of the aging process, while those with negative values are either produced or represent a greater relative contribution to the aged sample). Peaks in lighter colors were present in the XCMS analysis but were found to be present in significant amounts in the blank sample. Many of these peaks that were found in the blank extend past the scale of the plot but were cut off to focus on species associated with $\mathrm{BB}$ aerosol. Compounds having an absolute difference greater than $0.5 \%$ have been labeled. There is very little change for combustion at $800^{\circ} \mathrm{C}$, while $500^{\circ} \mathrm{C}$ shows a net removal of many compounds.

Smoldering-dominated burns were also examined for other nitro-aromatic species. Methyl nitrocatechol, which has been identified as a tracer for BB SOA (Iinuma et al., 2010), and nitroguaiacol both have the formula of $\mathrm{C}_{7} \mathrm{H}_{7} \mathrm{NO}_{4}$ and would have an $(\mathrm{M}-\mathrm{H})^{-}$peak at $m / z$ 168.0297. Fresh eucalyptus had two peaks at retention times of 7.71 and $9.31 \mathrm{~min}$, while acacia only had a single peak at $9.30 \mathrm{~min}$.
Using the exact mass and the RT, this peak at 9.30 min has been identified as 4-methyl-5-nitrocatechol, so the $7.71 \mathrm{~min}$ peak must be another isomer produced in fresh combustion. Since this compound must be more polar to elute earlier, it may be the 4-, 5-, or 6- isomer of nitroguaiacol (Bluvshtein et al., 2017; Kitanovski et al., 2012a). Upon aging, both fuels had two peaks with smaller absolute abundances 
Table 4. The slope of absorption vs. wavelength and the Angstrom absorption exponent for each sample, as measured by the UV-vis spectrum during chemical analysis (normalized) and during CRDS-nephelometer analysis (in situ). AAE was determined for the wavelength range $500 \mathrm{~nm} \leq \lambda \leq 570 \mathrm{~nm}$.

\begin{tabular}{|c|c|c|c|c|c|c|c|c|}
\hline & & & \multicolumn{3}{|c|}{$\begin{array}{c}\text { AAE } \\
\text { (normalized for UV-vis) }\end{array}$} & \multicolumn{3}{|c|}{$\begin{array}{c}\text { Slope } \\
\left(\times 10^{-5} \mathrm{~nm}^{-1} \text { for UV-vis, }\right. \\
\left.\times 10^{-16} \mathrm{~m}^{2} \mathrm{~nm}^{-1} \text { per particle for CRDS-neph }\right)\end{array}$} \\
\hline & & & Acacia & Eucalyptus & Olive & Acacia & Eucalyptus & Olive \\
\hline \multirow[t]{4}{*}{ UV-vis } & $500^{\circ} \mathrm{C}$ & Fresh & $5.55 \pm 1.21$ & $9.53 \pm 0.72$ & $9.10 \pm 0.64$ & $-23.7 \pm 4.8$ & $-24.6 \pm 1.9$ & $-20.6 \pm 4.3$ \\
\hline & & Aged & $-0.12 \pm 1.25$ & $-1.87 \pm 1.25$ & - & $-2.15 \pm 9.52$ & $10.3 \pm 8.8$ & - \\
\hline & $800^{\circ} \mathrm{C}$ & Fresh & $0.40 \pm 0.60$ & $0.91 \pm 0.51$ & $0.22 \pm 0.84$ & $-48.5 \pm 60.3$ & $-120 \pm 69$ & $-34.5 \pm 76.6$ \\
\hline & & Aged & $-0.13 \pm 0.49$ & $-1.88 \pm 1.01$ & - & $4.33 \pm 70.5$ & $145 \pm 91$ & - \\
\hline \multirow[t]{4}{*}{ CRDS-neph $(300 \mathrm{~nm})$} & $500^{\circ} \mathrm{C}$ & Fresh & $2.52 \pm 0.27$ & $1.71 \pm 0.18$ & $1.32 \pm 0.33$ & $-1.98 \pm 0.21$ & $-2.02 \pm 0.21$ & $-1.63 \pm 0.412$ \\
\hline & & Aged & $-3.25 \pm 0.98$ & $-4.20 \pm 3.12$ & - & $1.29 \pm 0.4$ & $0.46 \pm 0.42$ & - \\
\hline & $800^{\circ} \mathrm{C}$ & Fresh & $0.57 \pm 0.25$ & $0.66 \pm 0.22$ & $0.25 \pm 0.15$ & $-0.57 \pm 0.25$ & $-1.64 \pm 0.53$ & $-0.620 \pm 0.367$ \\
\hline & & Aged & $-5.54 \pm 0.53$ & $0.77 \pm 0.14$ & - & $1.81 \pm 0.16$ & $-2.98 \pm 0.55$ & - \\
\hline
\end{tabular}

at 9.5-9.6 and $10.0 \mathrm{~min}$. The $9.5-9.6 \mathrm{~min}$ peak is likely a slightly shifted 4-methyl-5-nitrocatechol, suggesting both a primary and secondary source of the compound. Based on previous observations of $\mathrm{BB}$ aerosol, the $10.0 \mathrm{~min}$ peak is either 3-methyl-6-nitrocatechol, 3-methyl-5-nitrocatechol, or 4-nitroguaiacol, whose sensitivity can be altered for it to elute either before or after 4-methyl-5-nitrocatechol (Bluvshtein et al., 2017; Kitanovski et al., 2012a). Nitrophenol $\left(\mathrm{C}_{6} \mathrm{H}_{5} \mathrm{NO}_{3},(\mathrm{M}-\mathrm{H})^{-}\right.$at $\mathrm{m} / z$ 138.0191) and nitrocresol $\left(\mathrm{C}_{7} \mathrm{H}_{7} \mathrm{NO}_{3},(\mathrm{M}-\mathrm{H})^{-}\right.$at $\left.m / z, 152.0348\right)$ are secondary products of phenol and cresol, respectively. Neither was observed for fresh eucalyptus and acacia. There are at least two forms of methyl nitrophenol in aged acacia (RT of 10.15 and $10.46 \mathrm{~min}$ ) and only one (RT $10.47 \mathrm{~min}$ ) in aged eucalyptus. Several isomers have been observed in BB aerosol in previous studies, including 3-methyl-4-, 2-methyl-4-, and 2methyl-6-nitrophenol (Bluvshtein et al., 2017; Kitanovski et al., 2012a). The peak with an RT of $\sim 10.46$ was likely a slightly shifted 4-nitro-o-cresol, which was a standard compound run during the analysis of fresh BB aerosol and had an RT of $10.30 \mathrm{~min}$. One nitrophenol peak at $9.37 \mathrm{~min}$ was observed in aged acacia, while aged eucalyptus did not exhibit any nitrophenol. This had a different RT than the 2nitrophenol standard, which had an RT of 10.05 min, suggesting it was some other isomer. Nitronaphthol $\left(\mathrm{C}_{10} \mathrm{H}_{7} \mathrm{NO}_{3}\right.$, $(\mathrm{M}-\mathrm{H})^{-}$at $m / z$ 188.0348) was not observed in any spectra.

\subsection{UV-visible analysis of fresh versus aged emissions}

In the companion paper Part 1 of this work, we found, as expected, that the SSA of eucalyptus and acacia increased after photochemical aging for $12 \mathrm{~h}$. For instance, $300 \mathrm{~nm}$ particles from eucalyptus combustion at $500^{\circ} \mathrm{C}$ went from an SSA of $\sim 0.67$ to almost unity, with only a slight increase due to the presence of VOCs. Acacia increased from $\sim 0.78$ to $0.90-0.95$ after aging, with no apparent change due to
VOCs. Since these measurements were size-selected and this increase was observed for all selected sizes, the SSA change could not be attributed to bulk changes within the aerosol, such as particle coagulation. Such an increase in SSA resulting from morphology changes alone seems implausible, so the particles themselves must become less absorbing with age. This would be because of a loss of absorbing compounds in the $500-570 \mathrm{~nm}$ region, the formation of non-absorbing SOA that alters the real portion of the refractive index, or both. In this section, we discuss how these changes in molecular composition affect the integrated UV-visible absorption spectrum and how these relate to the SSA of in situ aerosol studied in Part 1 of this work.

Schuster et al. (2016) found a strong correlation between $\mathrm{AAE}$ and the spectral variability of the refractive index of BB aerosols $\left(\kappa_{440} / \kappa_{700}\right)$, with a linear correlation of $R \geq$ 0.939 . BrC is spectrally dependent, with a greater imaginary part of the refractive index at $440 \mathrm{~nm}\left(\kappa_{440}\right)$ than the red region of the spectrum $\left(\kappa_{700}\right)$. Figure 4 a shows that UV absorption dominates for fresh BB aerosol combusted at $500^{\circ} \mathrm{C}$, with a negative slope in the $500-570 \mathrm{~nm}$ range, indicating the presence of $\mathrm{BrC}$ can alter the absorption in the midvisible region. This is corroborated by large in situ values of AAE (1.5) for these samples as seen in Table 4. BC, on the other hand, is spectrally independent $\left(\kappa_{440} / \kappa_{700} \approx 1\right)$ and has AAE values between 0.5 and 1.5 , as seen for the CRDS measurements in Table 4. This is corroborated by Fig. 4b and Table 4, which show that absorption in this range has a slope of zero within the measurement uncertainty for fresh BB aerosol combusted at $800^{\circ} \mathrm{C}$; all are within $1 \sigma$, except olive, which is within $2 \sigma$. The NAAE values based on UVvis measurements of molecular chromophores do not conform to this trend at $800^{\circ} \mathrm{C}$; however, this is likely because they have been normalized. Lastly, AAE can reach negative values when absorption is higher at longer wavelengths (near $700 \mathrm{~nm}$ ). Table 4 suggests that as BB aerosols are aged in the 
presence of UV light, they become more absorbing at longer wavelengths (except for eucalyptus combusted at $800^{\circ} \mathrm{C}$, as measured by CRDS). This could be caused by the formation of species that absorb at such long wavelengths, such as nitro-aromatic species and functionalized PAHs, or lensing effects from hygroscopic growth (Fleming et al., 2020; Liu et al., 2017).

For both eucalyptus and acacia combusted at $500^{\circ} \mathrm{C}$, the greatest loss of UV absorptivity, as seen in Fig. 5a, happens between 260 and $350 \mathrm{~nm}$, peaking at $\sim 290 \mathrm{~nm}$. Many of the lignin pyrolysis products are consumed upon aging due to either photo-bleaching or oxidation. Previous work has shown a reduction in $\mathrm{BrC}$ absorptivity due to photochemical aging (Sumlin et al., 2017) and OH oxidation (Dasari et al., 2019; Schnitzler and Abbatt, 2018). Most of these compounds absorb in the UV between 200 and $350 \mathrm{~nm}$, with the notable exception of coniferaldehyde and sinapaldehyde, which both peak near $340-345 \mathrm{~nm}$ and absorb past $400 \mathrm{~nm}$ (Fleming et al., 2020).

\subsection{Chromatographic analysis of potential chromophores in the visible}

In addition to examining the integrated spectrum, we can also focus on potential chromophores that absorb in the 500$570 \mathrm{~nm}$ region of the spectrum. Considering that flamingdominated combustion shows little in the way of absorbing species and the abundance of these species decreases upon aging, only fresh emissions from combustion at $500^{\circ} \mathrm{C}$ will be examined. Figure 6 shows the extracted wavelength chromatogram for the 500-510 nm region, where absorption would be most intense over this range, for eucalyptus and acacia combusted at $500^{\circ} \mathrm{C}$. This chromatogram has been background-subtracted by the filter blank, and, given that the amount of aerosol deposited on these filters was not measured, no scaling was applied. Remarkably, only a few peaks dominate the chromatogram, though there are likely several low-abundance and indistinct peaks at 11-13 min. The UVvisible absorption spectra for each designated peak in Fig. 6 are given in Fig. S4. As can be seen in Fig. 6, several of these species have similar retention times. A comparison was made between these peaks with respect to elution time. Peaks $A$ and $H$, despite coming from different fuels, show similar retention times and UV spectra, as can be seen in Fig. S5. The same can be said for peaks $B, C, I$, and $J$, which have well-separated peaks at $\sim 340$ and $\sim 485 \mathrm{~nm}$ with a gradual decrease to $600 \mathrm{~nm}$. Peaks $D, E$, and $K$ also have the same general appearance and may be related to $B, C, I$ and $J$, but they are somewhat broader and peak at slightly shorter wavelengths ( 332 and $\sim 480 \mathrm{~nm}$ ).

To determine which species produced the absorption features shown in Fig. 6, mass spectra at the absorption maxima were examined and assessed based on the peak height in the mass spectra, how well the retention times of extracted ion chromatograms matched the extracted visible wavelength chromatogram, and if a compound can be reasonably thought to absorb in the $500-510 \mathrm{~nm}$ region. Assignments using this method are tenuous given that species detected by the DAD may not be seen by negative-mode ESI-MS. Additionally, many of the species described below have additional peaks outside those described, suggesting that not all isomers corresponding to a given formula absorb in this region. The extracted ion and visible chromatograms (shown in Fig. 6) are in Fig. S6a for eucalyptus. Peak $A$ is either $\mathrm{C}_{9} \mathrm{H}_{10} \mathrm{O}_{3}(m / z$ 165.0559), tentatively assigned earlier, and/or $\mathrm{C}_{9} \mathrm{H}_{12} \mathrm{O}_{4}(\mathrm{~m} / z$ 183.0658), which could be an isomer of trimethoxyphenol or dimethoxy methyl catechol. Several isomers of $\mathrm{C}_{9} \mathrm{H}_{10} \mathrm{O}_{3}$ are known to only absorb below $240 \mathrm{~nm}$, though veratraldehyde and caffeyl alcohol UV-visible spectra have not been measured, nor has trimethoxyphenol or dimethoxy methyl catechol for $\mathrm{C}_{9} \mathrm{H}_{12} \mathrm{O}_{4}$. A $\mathrm{C}_{9} \mathrm{H}_{10} \mathrm{O}_{3}$ isomer may also contribute to peak $B$, and, while $\mathrm{C}_{8} \mathrm{H}_{10} \mathrm{O}_{2}(m / z, 137.0612)$ is more abundant at peak $B$ and previously identified as several isomers in this work, none would absorb in this region. Likewise, $\mathrm{C}_{10} \mathrm{H}_{10} \mathrm{O}_{2}(\mathrm{~m} / z$ 161.0604) elutes with peak $B$, which may be methoxycinnamaldehyde, methylcinnamic acid, or methylhydrocoumarin. While the spectra of those compounds have not been previously measured, it is unlikely that they would absorb in this region either. One compound that could weakly absorb in the visible and elutes at peak $B$ is hydroxycoumarin $\left(\mathrm{C}_{9} \mathrm{H}_{6} \mathrm{O}_{3}, m / z\right.$ 161.0244). One such compound, umbelliferone, absorbs to $\sim 420 \mathrm{~nm}$ (Abu-Eittah and El-Tawil, 1985), though a number of isomers are present that may have somewhat different spectra.

Several species show peaks in the mass chromatogram that correspond to peaks $B-F$, including $\mathrm{C}_{10} \mathrm{H}_{8} \mathrm{O}_{3}$ ( $m / z$ 175.0405), $\mathrm{C}_{11} \mathrm{H}_{8} \mathrm{O}_{3}\left(m / z\right.$ 187.0401), and $\mathrm{C}_{11} \mathrm{H}_{10} \mathrm{O}_{3}$ $\left(m / z\right.$ 189.0565). The species corresponding to $\mathrm{C}_{10} \mathrm{H}_{8} \mathrm{O}_{3}$ could be methoxycoumarin or methylhydroxycoumarin, though these species mainly absorb below $\sim 450 \mathrm{~nm}$ (AbuEittah and El-Tawil, 1985) and may only absorb very weakly above $500 \mathrm{~nm}$ if at all. Naphthalenetriol is a much more likely candidate for $\mathrm{C}_{10} \mathrm{H}_{8} \mathrm{O}_{3}$ given its extended and functionalized aromatic system, though a spectrum for any of its isomers has not been measured. The less functionalized 1,4naphthalenediol absorbs to $\sim 680 \mathrm{~nm}$ (Linstrom and Mallard, 2020). The structures attributable to $\mathrm{C}_{11} \mathrm{H}_{8} \mathrm{O}_{3}$ could be hydroxynaphthoic acid, acetylcoumarin, or methylcoumarinaldehyde, but none of these compounds absorb above $410 \mathrm{~nm}$ (Donovalová et al., 2012). Still, several of these compounds are yellow solids in their pure forms according to their safety data sheets (SDSs), suggesting they have some interaction with visible light. Similarly, an indistinct number of peaks associated with $\mathrm{C}_{11} \mathrm{H}_{10} \mathrm{O}_{3}$ are found within these retention times, which may be isomers of methylmethoxycoumarin or dimethylhydroxycoumarin, none of which have previously measured spectra. Peaks in the vicinity of peaks $F$ and $G$ correspond to $\mathrm{C}_{12} \mathrm{H}_{10} \mathrm{O}_{3}(m / z 201.0554)$ as methoxynaphthoic acid or methoxyhydroxynaphthaldehyde. No UV- 

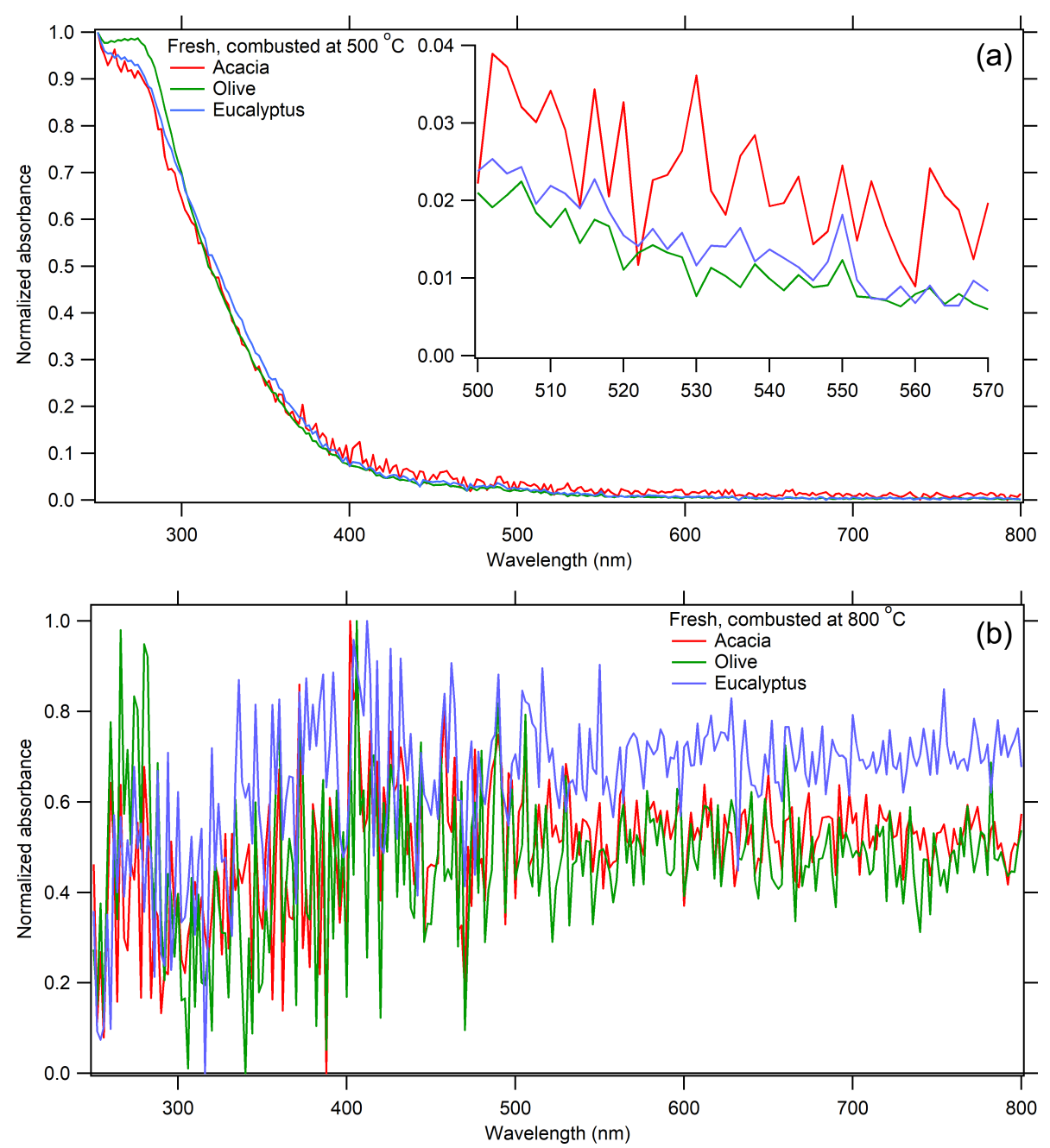

Figure 4. The normalized UV-visible spectra for fresh acacia-, olive-, and eucalyptus-derived $\mathrm{BB}$ aerosol combusted at $500{ }^{\circ} \mathrm{C}$ (a) and $800^{\circ} \mathrm{C}$ (b). These spectra have been averaged over the entire chromatogram, background-subtracted, and normalized, as described in Sect. 2.6.

visible spectra are available for these compounds, and, while some spectra are available for related compounds such as 1and 2-naphthoic acid (Linstrom and Mallard, 2020), these spectra seem truncated at $\sim 350 \mathrm{~nm}$. More telling is the SDS descriptions for these substituted naphthaldehydes and naphthoic acids, which are light yellow, yellow, and light brown. This suggests that their absorption extends into the visible and possibly into the $500 \mathrm{~nm}$ region.

One set of isomers in the vicinity of peaks $C$ through $F$ corresponds to the formula of $\mathrm{C}_{11} \mathrm{H}_{6} \mathrm{O}_{3}(\mathrm{~m} / z$ 185.0256). Given the high degree of unsaturation $(\mathrm{DBE}=9)$, these can only be furanocoumarins, which have a fused furan and benzene ring. Two common isomers of these species are psoralen and angelicin. While these species do not absorb in this region of this visible, they are strong absorbers below $370 \mathrm{~nm}$ (Rutan et al., 2018) and have not been previously identified as $\mathrm{BrC}$ species in $\mathrm{BB}$ aerosol. The peaks for nitroguaiacol and methylnitrocatechol, discussed earlier in this work, do not align well with peaks in Fig. 6.

Fresh acacia combusted at $500^{\circ} \mathrm{C}$ underwent a similar analysis, as shown in Fig. S6b. All the previously mentioned extracted ion chromatograms appear very similar for acacia, with the main difference being that the ion abundance for acacia was smaller by a factor or 2-4. Most ions had similar temporal profiles as eucalyptus with the exception of $\mathrm{C}_{11} \mathrm{H}_{10} \mathrm{O}_{3}(\mathrm{~m} / z$ 189.0565), which only matched peak $K$ and onwards. Given this, it is very likely that peaks with similar DAD retention times are produced by the same species, and peak $A$ corresponds with peak $H, B$ with $I, C$ with $J$, and $E$ with $K$. 

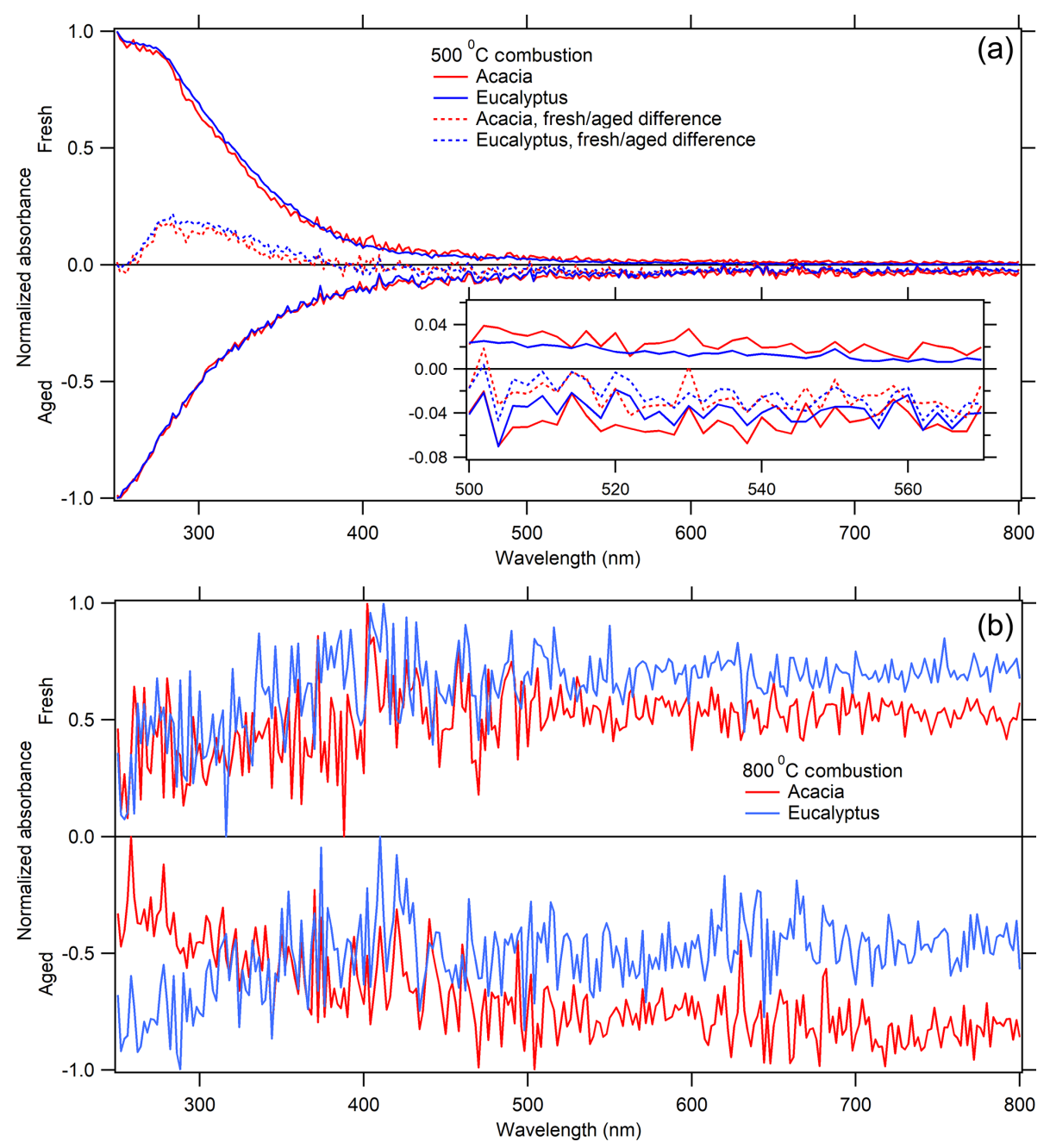

Figure 5. The UV-visible spectrum for each fuel combusted at $500^{\circ} \mathrm{C}$ (a) and $800^{\circ} \mathrm{C}$ (b), showing the result from fresh combustion with positive values and photochemically aged with negative values. These spectra have been averaged over the entire chromatogram, backgroundsubtracted, and normalized, as described in Sect. 2.6. The differences between them are highlighted with the dashed line, and an enlargement of the $500-570 \mathrm{~nm}$ region is presented in the inset.

\section{Conclusions}

When both fuels in this work were efficiently combusted at $800^{\circ} \mathrm{C}$, the chemical characterization of fresh $\mathrm{BB}$ aerosol revealed very little apparent difference between the two species - eucalyptus and acacia. The higher SSA observed for eucalyptus was not attributed to it containing more lowabundance species but some set of compounds that were not being captured in this analysis. This could be due to a prevalence of low-abundance species, semi-volatile compounds lost during sample processing (Chen et al., 2017), or insensitivity to ionization in the negative ion mode of our UPLC/DAD-ESI-HR-QTOFMS technique. A compound such as eucalyptol, which does not absorb in the UV or visible, could significantly alter the real portion of the refractive index of aerosols but would not be apparent using negativeion-mode ESI-MS given its lack of basic functionality.
Comparing these species combusted at $500^{\circ} \mathrm{C}$ revealed many species differentiated by their mass and chromatographic retention time (i.e., different isomers possessing the same formula). This work focused on compounds that were significantly different between fuel types, which had scaled intensity differences greater than $0.5 \%$. Both samples had a variety of compounds in common, such as lignin pyrolysis products, distillation products, and cellulose breakdown products. Only one isomer of dihydroxybenzene was observed for both fuels, which is either catechol (Simoneit, 2002) or resorcinol (Yokelson et al., 2013). Several lignin pyrolysis products and distillation products are more prevalent in eucalyptus than acacia, while pyrolysis products of cellulose and at least one nitro-aromatic species (nitroanisole, nitrocresol, or nitrobenxyl alcohol) were more prevalent in acacia. When both fuels and olive were examined for their sinapaldehyde and coniferaldehyde content, it was found 


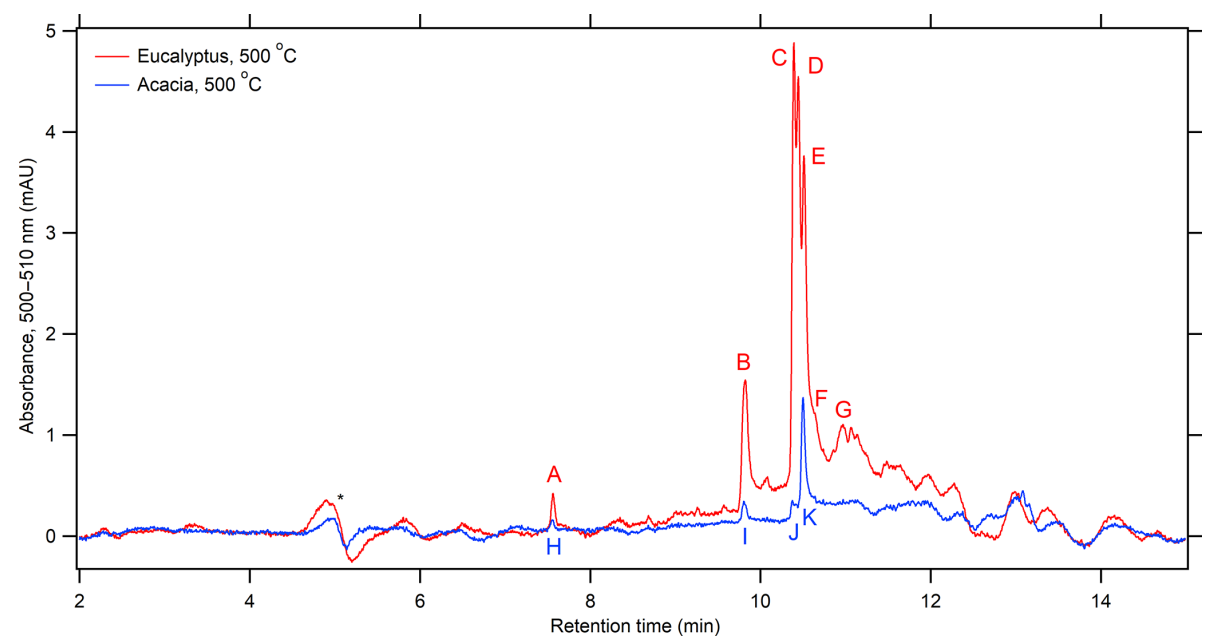

Figure 6. The extracted wavelength chromatogram for the $500-510 \mathrm{~nm}$ region for each fuel freshly combusted at $500^{\circ} \mathrm{C}$. The peak with the asterisk is an artifact from background subtraction.

that coniferaldehyde was more abundant by a factor of 1.63.4 , depending on the species. Given that all three are angiosperms, this observation is counter to observations made by Fleming et al. (2020), though it is worth noting that their results were in terms of absorption intensity instead of ion intensity. Given that chromophores, such as lignin pyrolysis and distillation products, are more prevalent in eucalyptus than acacia, which has a higher abundance of nonchromophores derived from sugars and cellulose, one would assume that eucalyptus would be more absorbing in the visible (i.e., have a lower SSA) than acacia. Despite this analysis not capturing absolute amounts of OA, acacia was found to have an SSA that is higher than eucalyptus by 0.1 to 0.2 , which is consistent with these observations. This suggests that acacia has either larger absolute amounts of nonchromophore compounds or eucalyptus has a greater quantity of chromophores whose absorptive properties extend to the 500-570 nm region of the visible spectrum.

In examining the effects of aging in the presence of UV light and anthropogenic VOCs, it is clear from Fig. 2 (eucalyptus) and Fig. 3 (acacia) that the amount of $\mathrm{BrC}$ decreases as the sample ages for combustion at $500^{\circ} \mathrm{C}$, and very few changes are occurring for particles produced from combustion at $800^{\circ} \mathrm{C}$. For both eucalyptus and acacia, an isomer of dihydroxybenzene, such as resorcinol or catechol, was removed to the highest degree from the fresh BB aerosol. Both of these species have relatively broad UV absorption spectra, extending from the vacuum UV to $\sim 292 \mathrm{~nm}$, with a peak at $275 \mathrm{~nm}$ and another at shorter wavelengths (Dewar et al., 1958). This is where most of the reduction of UV absorption is occurring. While this could suggest that these two compounds are responsible for a significant portion of the bleaching effect, there are a great number of compounds that absorb in a similar wavelength range, so that could not be conclusively stated. The removal of dihydroxybenzene was investigated by examining spectra for a known reaction product, dihydroxynitrobenzene (e.g., nitrocatechol). Results for both fuels suggest a small amount was produced by primary emissions, but it was mainly a product of secondary formation. The second most removed compound for eucalyptus was the distillation product benzoic acid and the lignin pyrolysis product hydroxybenzaldehyde. Several eucalyptus distillation products are also sensitive to aging that have not been previously observed, such as seven isomers of methoxyand/or methylhydroxycoumarin and all six isomers of hydroxycoumarin, of which only one has been previously observed. The second most consumed compound for acacia was one isomer that is likely nitroanisole, nitrobenxyl alcohol, or nitrocresol, which was not seen previously and is a primary product of in-flame $\mathrm{NO}_{x}$ chemistry. Generally, both fuels were dominated by loss of chromatophoric lignin pyrolysis and distillation products. Focusing on nitro-aromatic species, one isomer of nitrophenol was produced during the aging of acacia combusted at $500^{\circ} \mathrm{C}$, while none was produced for eucalyptus. Despite being thought of as a tracer for BB SOA (linuma et al., 2010), there is evidence for both primary emission and secondary production of 4-methyl-5nitrocatechol.

Not surprisingly, the associated absorbance from these chromophores, mostly from 200 to $350 \mathrm{~nm}$, also attenuates with respect to age, as seen in Fig. 5. This may be caused in part by the photo-bleaching effect created by the irradiation of UV light for $12 \mathrm{~h}$, heterogeneous $\mathrm{OH}$ oxidation, and SOA formation of non-chromophores. As stated in Part 1 of this companion paper, ignition temperature is the leading factor for differences in the SSA of the resulting BB aerosol, which is supported by the associated MCE values at each temperature. At lower temperatures, combustion is less efficient and releases more emissions in the form of the lignin pyrolysis and distillation products, which are primarily re- 
sponsible for the change in absorption seen between fresh and aged samples, as they absorb strongly in the UV. Some larger compounds were discovered, but only one functionalized PAH was successfully identified. The identification of other functionalized PAHs would be beneficial in determining any changes to SSA because of photochemical aging with anthropogenic VOCs present, as these compounds exhibit wide absorption spectra extending into the visible.

An attempt was also made to identify which species produce absorption at wavelengths longer than $500 \mathrm{~nm}$. An extracted wavelength chromatogram for $500-510 \mathrm{~nm}$ shows that only a few peaks dominate the absorption from fresh emissions of combustion at $500^{\circ} \mathrm{C}$. Both acacia and eucalyptus have common absorbing species, as shown by peaks with common retention times, similar UV-visible spectra, and extracted ion chromatograms. By comparing the retention times of extracted ion and wavelength chromatograms, several species were tentatively suggested for contributing to absorption in this wavelength range. This includes functionalized courmarin species (hydroxy-, methoxy- methylhydroxy, methylmethoxy-, etc.), naphthalenetriol, and methoxyhydroxynaphthaldehyde or methoxynaphthoic acid. UV spectra available from the literature for several of these species and/or related compounds seem truncated and are very likely to extend into this visible region of the spectrum, which highlights the need for broadband UV-visible spectral measurements of these compounds. While not important for absorption in this visible region, a novel set of compounds was found that could be strong $\mathrm{BrC}$ species - furanocoumarins.

As shown in companion paper Part 1, there are changes in the SSA that occur in response to dark aging. Future work will examine those processes from a molecular standpoint and how they are different from photochemical aging. Given that there was no SOA enhancement or significant difference in SSA observed for the addition of anthropogenic VOCs, it is unlikely that even these elevated concentrations would alter the molecular constituents. However, this should be confirmed with at least one example.

Data availability. The data for this work are provided in the Supplement (Excel spreadsheet).

Supplement. The supplement related to this article is available online at: https://doi.org/10.5194/acp-20-10169-2020-supplement.

Author contributions. DMS and TC conducted the experiments, and MNF, TC, and DMS analyzed the data. MNF, JDS, and SB designed the experiments and contributed to writing and editing. RPP contributed to the data analysis and interpretation.
Competing interests. The authors declare that they have no conflict of interest.

Acknowledgements. This material is based upon work supported by the National Science Foundation under grant no. 1555479. We acknowledge the help by Sivakumar Venkatraman at the University of Kwa-Zulu Natal, School of Chemistry and Physics, South Africa, for providing us with the VOC emission data for South Africa.

Financial support. This research has been supported by the National Science Foundation, Directorate for Geosciences (grant no. NSF-AGS 1555479).

Review statement. This paper was edited by Joel Thornton and reviewed by two anonymous referees.

\section{References}

Abu-Eittah, R. H. and El-Tawil, B. A. H.: The electronic absorption spectra of some coumarins. A molecular orbital treatment, Can. J. Chem., 63, 1173-1179, https://doi.org/10.1139/v85-200, 1985.

Akagi, S. K., Yokelson, R. J., Wiedinmyer, C., Alvarado, M. J., Reid, J. S., Karl, T., Crounse, J. D., and Wennberg, P. O.: Emission factors for open and domestic biomass burning for use in atmospheric models, Atmos. Chem. Phys., 11, 4039-4072, https://doi.org/10.5194/acp-11-4039-2011, 2011.

Andreae, M. O. and Gelencsér, A.: Black carbon or brown carbon? The nature of light-absorbing carbonaceous aerosols, Atmos. Chem. Phys., 6, 3131-3148, https://doi.org/10.5194/acp-63131-2006, 2006.

Andreae, M. O. and Merlet, P.: Emission of trace gases and aerosols from biomass burning, Global Biogeochem. Cy., 15, 955-966, https://doi.org/10.1029/2000GB001382, 2001.

Bergstrom, R. W., Pilewskie, P., Russell, P. B., Redemann, J., Bond, T. C., Quinn, P. K., and Sierau, B.: Spectral absorption properties of atmospheric aerosols, Atmos. Chem. Phys., 7, 5937-5943, https://doi.org/10.5194/acp-7-5937-2007, 2007.

Bi, X., Simoneit, B. R. T., Sheng, G., Ma, S., and Fu, J.: Composition and major sources of organic compounds in urban aerosols, Atmos. Res., 88, 256-265, https://doi.org/10.1016/j.atmosres.2007.11.017, 2008.

Bluvshtein, N., Lin, P., Flores, J. M., Segev, L., Mazar, Y., Tas, E., Snider, G., Weagle, C., Brown, S. S., Laskin, A., and Rudich, Y.: Broadband optical properties of biomassburning aerosol and identification of brown carbon chromophores, J. Geophys. Res.-Atmos., 122, 5441-5456, https://doi.org/10.1002/2016JD026230, 2017.

Bond, T. C. and Bergstrom, R. W.: Light Absorption by Carbonaceous Particles: An Investigative Review, Aerosol Sci. Tech., 40, 27-67, https://doi.org/10.1080/02786820500421521, 2006.

Budisulistiorini, S. H., Riva, M., Williams, M., Chen, J., Itoh, M., Surratt, J. D., and Kuwata, M.: Light-Absorbing Brown Carbon Aerosol Constituents from Combustion of Indonesian Peat and Biomass, Environ. Sci. Technol., 51, 4415-4423, https://doi.org/10.1021/acs.est.7b00397, 2017. 
Chen, J., Li, C., Ristovski, Z., Milic, A., Gu, Y., Islam, M. S., Wang, S., Hao, J., Zhang, H., He, C., Guo, H., Fu, H., Miljevic, B., Morawska, L., Thai, P., Lam, Y. F., Pereira, G., Ding, A., Huang, X., and Dumka, U. C.: A review of biomass burning: Emissions and impacts on air quality, health and climate in China, Sci. Total Environ., 579, 1000-1034, https://doi.org/10.1016/j.scitotenv.2016.11.025, 2017.

Chen, Y. and Bond, T. C.: Light absorption by organic carbon from wood combustion, Atmos. Chem. Phys., 10, 1773-1787, https://doi.org/10.5194/acp-10-1773-2010, 2010.

Collier, S., Zhou, S., Onasch, T. B., Jaffe, D. A., Kleinman, L., Sedlacek, A. J., Briggs, N. L., Hee, J., Fortner, E., and Shilling, J. E.: Regional Influence of Aerosol Emissions from Wildfires Driven by Combustion Efficiency: Insights from the BBOP Campaign, Environ. Sci. Technol., 50, 8613, https://doi.org/10.1021/acs.est.6b01617, 2016.

Dasari, S., Andersson, A., Bikkina, S., Holmstrand, H., Budhavant, K., Satheesh, S., Asmi, E., Kesti, J., Backman, J., Salam, A., Bisht, D. S., Tiwari, S., Hameed, Z., and Gustafsson, Ö.: Photochemical degradation affects the light absorption of watersoluble brown carbon in the South Asian outflow, Sci. Adv., 5, eaau8066, https://doi.org/10.1126/sciadv.aau8066, 2019.

Dewar, M. J. S., Kubba, V. P., and Pettit, R.: 625. New heteroaromatic compounds. Part II. Boron compounds isoconjugate with indole, 2: 3-benzofuran, and thionaphthen, J. Chem. Soc., 30763079, https://doi.org/10.1039/JR9580003076, 1958.

Donovalová, J., Cigáň, M., Stankovičová, H., Gašpar, J., Danko, M., Gáplovský, A., and Hrdlovič, P.: Spectral Properties of Substituted Coumarins in Solution and Polymer Matrices, Molecules, 17, 3259-3276, https://doi.org/10.3390/molecules17033259, 2012.

Finewax, Z., de Gouw, J. A., and Ziemann, P. J.: Identification and Quantification of 4-Nitrocatechol Formed from $\mathrm{OH}$ and $\mathrm{NO}_{3}$ Radical-Initiated Reactions of Catechol in Air in the Presence of $\mathrm{NO}_{x}$ : Implications for Secondary Organic Aerosol Formation from Biomass Burning, Environ. Sci. Technol., 52, 1981-1989, https://doi.org/10.1021/acs.est.7b05864, 2018.

Fleming, L. T., Lin, P., Roberts, J. M., Selimovic, V., Yokelson, R., Laskin, J., Laskin, A., and Nizkorodov, S. A.: Molecular composition and photochemical lifetimes of brown carbon chromophores in biomass burning organic aerosol, Atmos. Chem. Phys., 20, 1105-1129, https://doi.org/10.5194/acp-201105-2020, 2020.

Fortner, E., Onasch, T., Canagaratna, M., Williams, L. R., Lee, T., Jayne, J., and Worsnop, D.: Examining the chemical composition of black carbon particles from biomass burning with SP-AMS, J. Aerosol Sci., 120, 12-21, https://doi.org/10.1016/j.jaerosci.2018.03.001, 2018.

Iinuma, Y., Böge, O., Gräfe, R., and Herrmann, H.: MethylNitrocatechols: Atmospheric Tracer Compounds for Biomass Burning Secondary Organic Aerosols, Environ. Sci. Technol., 44, 8453-8459, https://doi.org/10.1021/es102938a, 2010.

Jiang, H., Frie, A. L., Lavi, A., Chen, J. Y., Zhang, H., Bahreini, R., and Lin, Y.-H.: Brown Carbon Formation from Nighttime Chemistry of Unsaturated Heterocyclic Volatile Organic Compounds, Environ. Sci. Technol. Lett., 6, 184-190, https://doi.org/10.1021/acs.estlett.9b00017, 2019.

Kirchstetter, T. W., Novakov, T., and Hobbs, P. V.: Evidence that the spectral dependence of light absorption by aerosols is affected by organic carbon, J. Geophys. Res.-Atmos., 109, D21208, https://doi.org/10.1029/2004JD004999, 2004.

Kitanovski, Z., Grgić, I., Vermeylen, R., Claeys, M., and Maenhaut, W.: Liquid chromatography tandem mass spectrometry method for characterization of monoaromatic nitro-compounds in atmospheric particulate matter, J. Chromatogr. A, 1268, 35-43, https://doi.org/10.1016/j.chroma.2012.10.021, 2012a.

Kitanovski, Z., Grgić, I., Yasmeen, F., Claeys, M., and Čusak, A.: Development of a liquid chromatographic method based on ultraviolet-visible and electrospray ionization mass spectrometric detection for the identification of nitrocatechols and related tracers in biomass burning atmospheric organic aerosol, Rapid Commun. Mass Spectrom., 26, 793-804, https://doi.org/10.1002/rcm.6170, 2012b.

Kroflič, A., Huš, M., Grilc, M., and Grgić, I.: Underappreciated and Complex Role of Nitrous Acid in Aromatic Nitration under Mild Environmental Conditions: The Case of Activated Methoxyphenols, Environ. Sci. Technol., 52, 1375613765, https://doi.org/10.1021/acs.est.8b01903, 2018.

Kumar, N. K., Corbin, J. C., Bruns, E. A., Massabó, D., Slowik, J. G., Drinovec, L., Močnik, G., Prati, P., Vlachou, A., Baltensperger, U., Gysel, M., El-Haddad, I., and Prévôt, A. S. H.: Production of particulate brown carbon during atmospheric aging of residential wood-burning emissions, Atmos.Chem. Phys., 18, 17843-17861, https://doi.org/10.5194/acp-18-17843-2018, 2018.

Lambe, A. T., Ahern, A. T., Williams, L. R., Slowik, J. G., Wong, J. P. S., Abbatt, J. P. D., Brune, W. H., Ng, N. L., Wright, J. P., Croasdale, D. R., Worsnop, D. R., Davidovits, P., and Onasch, T. B.: Characterization of aerosol photooxidation flow reactors: heterogeneous oxidation, secondary organic aerosol formation and cloud condensation nuclei activity measurements, Atmos. Meas. Tech., 4, 445-461, https://doi.org/10.5194/amt-4445-2011, 2011.

Lambe, A. T., Cappa, C. D., Massoli, P., Onasch, T. B., Forestieri, S. D., Martin, A. T., Cummings, M. J., Croasdale, D. R., Brune, W. H., Worsnop, D. R., and Davidovits, P.: Relationship between Oxidation Level and Optical Properties of Secondary Organic Aerosol, Environ. Sci. Technol., 47, 6349-6357, https://doi.org/10.1021/es401043j, 2013.

Laskin, A., Laskin, J., and Nizkorodov, S. A.: Chemistry of Atmospheric Brown Carbon, Chem. Rev., 115, 4335-4382, https://doi.org/10.1021/cr5006167, 2015.

Laskin, A., Lin, P., Laskin, J., Fleming, L., and Nizkorodov, S.: Molecular Characterization of Atmospheric Brown Carbon, in: Multiphase Environmental Chemistry in the Atmosphere, edited by: Hunt, S. W., Laskin, A., and Nizkorodov, S. A., American Chemical Society, Washington, DC, 261-274, 2018.

Lee, H. J., Aiona, P. K., Laskin, A., Laskin, J., and Nizkorodov, S. A.: Effect of Solar Radiation on the Optical Properties and Molecular Composition of Laboratory Proxies of Atmospheric Brown Carbon, Environ. Sci. Technol., 48, 10217 10226, https://doi.org/10.1021/es502515r, 2014.

Lin, P., Laskin, J., Nizkorodov, S. A., and Laskin, A.: Revealing Brown Carbon Chromophores Produced in Reactions of Methylglyoxal with Ammonium Sulfate, Environ. Sci. Technol., 49, 14257-14266, https://doi.org/10.1021/acs.est.5b03608, 2015a.

Lin, P., Liu, J. M., Shilling, J. E., Kathmann, S. M., Laskin, J., and Laskin, A.: Molecular characterization of brown car- 
bon $(\mathrm{BrC})$ chromophores in secondary organic aerosol generated from photo-oxidation of toluene, Phys. Chem. Chem. Phys., 17, 23312, https://doi.org/10.1039/C5CP02563J, 2015b.

Lin, P., Aiona, P. K., Li, Y., Shiraiwa, M., Laskin, J., Nizkorodov, S. A., and Laskin, A.: Molecular Characterization of Brown Carbon in Biomass Burning Aerosol Particles, Environ. Sci. Technol., 50, 11815-11824, https://doi.org/10.1021/acs.est.6b03024, 2016.

Lin, P., Bluvshtein, N., Rudich, Y., Nizkorodov, S. A., Laskin, J., and Laskin, A.: Molecular Chemistry of Atmospheric Brown Carbon Inferred from a Nationwide Biomass Burning Event, Environ. Sci. Technol., 51, 11561-11570, https://doi.org/10.1021/acs.est.7b02276, 2017.

Lin, Y.-H., Budisulistiorini, S. H., Chu, K., Siejack, R. A., Zhang, H., Riva, M., Zhang, Z., Gold, A., Kautzman, K. E., and Surratt, J. D.: Light-Absorbing Oligomer Formation in Secondary Organic Aerosol from Reactive Uptake of Isoprene Epoxydiols, Environ. Sci. Technol., 48, 12012-12021, https://doi.org/10.1021/es503142b, 2014.

Linstrom, P. J. and Mallard, W. G. (Eds.): NIST Chemistry Web Book, https://doi.org/10.18434/T4D303, 2020.

Liu, D., Whitehead, J., Alfarra, M. R., Reyes-Villegas, E., Spracklen, D. V., Reddington, C. L., Kong, S., Williams, P. I., Ting, Y.-C., Haslett, S., Taylor, J. W., Flynn, M. J., Morgan, W. T., McFiggans, G., Coe, H., and Allan, J. D.: Black-carbon absorption enhancement in the atmosphere determined by particle mixing state, Nat. Geosci., 10, 184-188, https://doi.org/10.1038/ngeo2901, 2017.

Masamba, W. R. L., Henry, E. M. T., and Banda, W.: Composition and properties of essential oils from Eucalyptus camaldulensis and E. tereticornis, Malawi J. Sci. Technol., 6, 81-89, 2001.

May, A. A., McMeeking, G. R., Lee, T., Taylor, J. W., Craven, J. S., Burling, I., Sullivan, A. P., Akagi, S., Collett Jr., J. L., Flynn, M., Coe, H., Urbanski, S. P., Seinfeld, J. H., Yokelson, R. J., and Kreidenweis, S. M.: Aerosol emissions from prescribed fires in the United States: A synthesis of laboratory and aircraft measurements, J. Geophys. Res.-Atmos., 119, 1182611849, https://doi.org/10.1002/2014jd021848, 2014.

McClure, C. D., Lim, C. Y., Hagan, D. H., Kroll, J. H., and Cappa, C. D.: Biomass-burning-derived particles from a wide variety of fuels - Part 1: Properties of primary particles, Atmos. Chem. Phys., 20, 1531-1547, https://doi.org/10.5194/acp20-1531-2020, 2020.

McMeeking, G. R., Kreidenweis, S. M., Baker, S., Carrico, C. M., Chow, J. C., Collett, J. L., Hao, W. M., Holden, A. S., Kirchstetter, T. W., Malm, W. C., Moosmüller, H., Sullivan, A. P., and Wold, C. E.: Emissions of trace gases and aerosols during the open combustion of biomass in the laboratory, J. Geophys. Res.Atmos., 114, D19210, https://doi.org/10.1029/2009JD011836, 2009.

Mohr, C., Lopez-Hilfiker, F. D., Zotter, P., Prévôt, A. S. H., Xu, L., Ng, N. L., Herndon, S. C., Williams, L. R., Franklin, J. P., Zahniser, M. S., Worsnop, D. R., Knighton, W. B., Aiken, A. C., Gorkowski, K. J., Dubey, M. K., Allan, J. D., and Thornton, J. A.: Contribution of Nitrated Phenols to Wood Burning Brown Carbon Light Absorption in Detling, United Kingdom during Winter Time, Environ. Sci. Technol., 47, 6316-6324, https://doi.org/10.1021/es400683v, 2013.
Moise, T., Flores, J. M., and Rudich, Y.: Optical Properties of Secondary Organic Aerosols and Their Changes by Chemical Processes, Chem. Rev., 115, 4400-4439, https://doi.org/10.1021/cr5005259, 2015.

Nguyen, T. B., Lee, P. B., Updyke, K. M., Bones, D. L., Laskin, J., Laskin, A., and Nizkorodov, S. A.: Formation of nitrogen- and sulfur-containing light-absorbing compounds accelerated by evaporation of water from secondary organic aerosols, J. Geophys. Res.-Atmos., 117, D01207, https://doi.org/10.1029/2011jd016944, 2012.

Oyem, A. A. and Igbafe, A. F.: Analysis of Atmospheric Aerosol Loading over Nigeria, Environ. Res. J., 4, 145-156, 2010.

Qin, Y. M., Tan, H. B., Li, Y. J., Li, Z. J., Schurman, M. I., Liu, L., Wu, C., and Chan, C. K.: Chemical characteristics of brown carbon in atmospheric particles at a suburban site near Guangzhou, China, Atmos. Chem. Phys., 18, 16409-16418, https://doi.org/10.5194/acp-18-16409-2018, 2018.

Reid, J., Koppmann, R., Eck, T., and Eleuterio, D.: A review of biomass burning emissions part II: intensive physical properties of biomass burning particles, Atmos. Chem. Phys., 5, 799-825, https://doi.org/10.5194/acp-5-799-2005, 2005.

Rutan, S. C., Venkatramani, C. J., and Stoll, D. R.: Peak Purity in Liquid Chromatography, Part I: Basic Concepts, Commercial Software, and Limitations, LCGC North America, 36, 100-110, 2018.

Saleh, R.: From Measurements to Models: Toward Accurate Representation of Brown Carbon in Climate Calculations, Curr. Pollut. Rep., 6, 90-104, https://doi.org/10.1007/s40726-020-001393, 2020.

Saleh, R., Hennigan, C. J., McMeeking, G. R., Chuang, W. K., Robinson, E. S., Coe, H., Donahue, N. M., and Robinson, A. L.: Absorptivity of brown carbon in fresh and photo-chemically aged biomass-burning emissions, Atmos. Chem. Phys., 13, 76837693, https://doi.org/10.5194/acp-13-7683-2013, 2013.

Saleh, R., Cheng, Z., and Atwi, K.: The BrownBlack Continuum of Light-Absorbing Combustion Aerosols, Environ. Sci. Technol. Lett., 5, 508-513, https://doi.org/10.1021/acs.estlett.8b00305, 2018.

Sareen, N., Moussa, S. G., and McNeill, V. F.: Photochemical Aging of Light-Absorbing Secondary Organic Aerosol Material, J. Phys. Chem. A, 117, 2987-2996, https://doi.org/10.1021/jp309413j, 2013.

Schnitzler, E. G. and Abbatt, J. P. D.: Heterogeneous OH oxidation of secondary brown carbon aerosol, Atmos. Chem. Phys., 18, 14539-14553, https://doi.org/10.5194/acp-18-14539-2018, 2018.

Schuster, G. L., Dubovik, O., Arola, A., Eck, T. F., and Holben, B. N.: Remote sensing of soot carbon - Part 2: Understanding the absorption Ångström exponent, Atmos. Chem. Phys., 16, 15871602, https://doi.org/10.5194/acp-16-1587-2016, 2016.

Simoneit, B. R. T.: Biomass burning - a review of organic tracers for smoke from incomplete combustion, Appl. Geochem., 17, 129162, https://doi.org/10.1016/S0883-2927(01)00061-0, 2002.

Simoneit, B. R. T., Elias, V. O., Kobayashi, M., Kawamura, K., Rushdi, A. I., Medeiros, P. M., Rogge, W. F., and Didyk, B. M.: Sugars - Dominant water-soluble organic compounds in soils and characterization as tracers in atmospheric particulate matter, Environ. Sci. Technol., 38, 5939-5949, https://doi.org/10.1021/es0403099, 2004. 
Smith, D. M., Fiddler, M. N., Sexton, K. G., and Bililign, S.: Construction and Characterization of an Indoor Smog Chamber for Measuring the Optical and Physicochemical Properties of Aging Biomass Burning Aerosols, Aerosol Air Qual. Res., 19, 467-483, https://doi.org/10.4209/aaqr.2018.06.0243, 2019.

Smith, D. M., Fiddler, M. N., Pokhrel, R. P., and Bililign, S.: Laboratory studies of fresh and aged biomass burning aerosol emitted from east African biomass fuels - Part 1: Optical properties, Atmos. Chem. Phys., 20, 10149-10168, https://doi.org/10.5194/acp-20-10149-2020, 2020.

Subramanian, P. A., Gebrekidan, A., and Nigussie, K.: Yield, contents and chemical composition variations in the essential oils of different Eucalyptus globulus trees from Tigray, Northern Ethiopia, J. Pharm. Biomed. Sci., 11, 1-6, 2012.

Sumlin, B. J., Pandey, A., Walker, M. J., Pattison, R. S., Williams, B. J., and Chakrabarty, R. K.: Atmospheric Photooxidation Diminishes Light Absorption by Primary Brown Carbon Aerosol from Biomass Burning, Environ. Sci. Technol. Lett., 4, 540-545, https://doi.org/10.1021/acs.estlett.7b00393, 2017.

Tautenhahn, R., Patti, G. J., Rinehart, D., and Siuzdak, G.: XCMS Online: A Web-Based Platform to Process Untargeted Metabolomic Data, Anal. Chem., 84, 5035-5039, https://doi.org/10.1021/ac300698c, 2012.

Teich, M., van Pinxteren, D., Wang, M., Kecorius, S., Wang, Z., Müller, T., Močnik, G., and Herrmann, H.: Contributions of nitrated aromatic compounds to the light absorption of watersoluble and particulate brown carbon in different atmospheric environments in Germany and China, Atmos. Chem. Phys., 17, 1653-1672, https://doi.org/10.5194/acp-17-1653-2017, 2017.

Tian, Z., Gold, A., Nakamura, J., Zhang, Z., Vila, J., Singleton, D. R., Collins, L. B., and Aitken, M. D.: Nontarget Analysis Reveals a Bacterial Metabolite of Pyrene Implicated in the Genotoxicity of Contaminated Soil after Bioremediation, Environ. Sci. Technol., 51, 7091-7100, https://doi.org/10.1021/acs.est.7b01172, 2017.
Tichy, M.: UV Atlas of Organic Compounds, in: UV Atlas of Organic Compounds/UV Atlas organischer Verbindungen, Springer US, Boston, MA, 5-605, 1967.

Vidovic, K., Lasic Jurkovic, D., Sala, M., Kroflic, A., and Grgic, I.: Nighttime Aqueous-Phase Formation of Nitrocatechols in the Atmospheric Condensed Phase, Environ. Sci. Technol., 52, 9722 9730, https://doi.org/10.1021/acs.est.8b01161, 2018.

Wang, Y., Hu, M., Wang, Y., Zheng, J., Shang, D., Yang, Y., Liu, Y., Li, X., Tang, R., Zhu, W., Du, Z., Wu, Y., Guo, S., Wu, Z., Lou, S., Hallquist, M., and Yu, J. Z.: The formation of nitro-aromatic compounds under high $\mathrm{NO}_{x}$ and anthropogenic VOC conditions in urban Beijing, China, Atmos. Chem. Phys., 19, 7649-7665, https://doi.org/10.5194/acp-19-7649-2019, 2019.

Yokelson, R. J., Burling, I. R., Gilman, J. B., Warneke, C., Stockwell, C. E., de Gouw, J., Akagi, S. K., Urbanski, S. P., Veres, P., Roberts, J. M., Kuster, W. C., Reardon, J., Griffith, D. W. T., Johnson, T. J., Hosseini, S., Miller, J. W., Cocker Iii, D. R., Jung, H., and Weise, D. R.: Coupling field and laboratory measurements to estimate the emission factors of identified and unidentified trace gases for prescribed fires, Atmos. Chem. Phys., 13, 89-116, https://doi.org/10.5194/acp-13-89-2013, 2013.

Zhang, X., Lin, Y.-H., Surratt, J. D., and Weber, R. J.: Sources, Composition and Absorption Ångström Exponent of Lightabsorbing Organic Components in Aerosol Extracts from the Los Angeles Basin, Environ. Sci. Technol., 47, 3685-3693, https://doi.org/10.1021/es305047b, 2013.

Zhao, R., Lee, A. K. Y., Huang, L., Li, X., Yang, F., and Abbatt, J. P. D.: Photochemical processing of aqueous atmospheric brown carbon, Atmos. Chem. Phys., 15, 6087-6100, https://doi.org/10.5194/acp-15-6087-2015, 2015. 